\title{
Numerical and Experimental Investigation of Deployment Behaviour of Folded Fin Mechanism based on the Dynamic Loading Conditions
}

MURAT AVCI ( $\square$ muratavci532@gmail.com )

TUBITAK SAGE https://orcid.org/0000-0003-3363-8636

\section{ÖZER TAGA}

TUBITAK Savunma Sanayii Arastirma ve Gelistirme Enstitusu

ÖMER KELEŞ

Gazi Universitesi Muhendislik Fakultesi

Original Article

Keywords: Folded Mechanism, Friction Coefficient, Multi Body Dynamics, Design of Experiment

Posted Date: June 17th, 2020

DOI: https://doi.org/10.21203/rs.3.rs-34954/v1

License: (c) (i) This work is licensed under a Creative Commons Attribution 4.0 International License.

Read Full License 


\title{
Numerical and Experimental Investigation of Deployment Behaviour of Folded Fin Mechanism based on the Dynamic Loading Conditions
}

\author{
Murat AVCI ${ }^{(1)^{*}}$, Ozer TAGA ${ }^{(1)}$, Omer KELEŞ ${ }^{(2)}$ \\ (1) The Scientific and Technical Research Council of Turkey-Defence Industries Research and Development \\ Institute ( TUBITAK-SAGE), Ankara, Turkey \\ (2) Department of Mechanical Engineering, Gazi University, 06570 Maltepe, Cankaya, Ankara, Turkey \\ * Corresponding Author Tel.+905466080331, murat.avci@tubitak.gov.tr
}

\begin{abstract}
In this study, the friction and damping values that arise during the deployment of the folded fin mechanism were obtained based on the experimental data. Although there are recommended values for friction in the literature, damping is a phenomenon that varies from system to system and must be obtained through test data. In this study, firstly, the mechanism was operated on the test device with a specific drive pressure and the actual drive pressure generated in the system was measured. The dynamic behaviour of the mechanism was recorded by a High-Speed camera system as well. Adams MBD (multi-body dynamics) was used to define the mechanism model and drive pressure data from the test was defined as input to the model. With the help of Adams DOE (Design of Experiments), certain intervals were defined for friction and damping, multiple analyses were carried out at the friction and damping intervals defined and total deployment time of the mechanism and the dynamic behaviours it exhibited during deployment were obtained. From these numerical results obtained, friction and damping values were obtained based on the model with the highest correlation and test results. The same mechanism was tested for different drive pressures with the specified friction and damping values and the results were compared to the numerical models. It was decided that the friction and damping values determined as a result of the comparison could be used in future numerical analyses.
\end{abstract}

Keywords: Folded Mechanism, Friction Coefficient, Multi Body Dynamics, Design of Experiment

\section{Introduction}

One of the design constraints to be considered when designing is volume constraint. Due to volume constraints, there may be conditions in which a system must be turned into a deployed position from closed position [1]. It is necessary to know the dynamic behaviour of a system designed under these volume constraints as it moves from a closed position to a deployed position. In order to determine the dynamic behaviour, the equation of motion of the system must be solved, too. Nagaraj et al. compared the mathematical model of the dynamic behaviour of a flexible system with two hinged joints that were designed to be folded due to volume constraints. With the finite element method, the joints were modelled as flexible and the equations of motion were derived from the Lagrangian formulas. The behaviour of the system was also investigated through rigid body and flexible body. It was emphasized that rigid body analyses were not very accurate because they ignored energy losses in joints [2].

There are more than one method to solve the equation of motion of a system. Gu et al used the finite segment method for the modelling of the line throwing rocket system. Dynamic model of the line throwing rocket system is based on the Kane's method [3]. Tiwari et al studied on a rigid body dynamics model for a representative howitzer system and used relatively simple experimental procedures to estimate principal design parameters of their dynamic system [4]. Tian et al. compared the dynamic analysis of a crank connecting rod mechanism using the Adams program in a numerical method and compared it with the analytical solution of the system's motion equation [5]. Wie et al. performed analytic modelling of the motion 
of the folding system of a space solar panel and its simulation with a DISCOS numerical analysis and compared the two results obtained [6]. Soykasap carried out the analytical analysis of dynamic deploying of a self-expandable composite rod and compared the results with empirical data. Instead of Explicit non-linear analysis, he solved the equation of motion of the bar by a simple analytical model [7]. Okuizumi and Yamamoto examined the centrifugal deploying of a helically folded membrane structure with experiments and simulations. The empirical and numerical results were compared to reveal the dynamic characteristics of the system and the validity of the numerical simulations was examined [8].

Brusa and Lemma solved the equation of motion in Adams and compared the results of numerical analysis to the empirical data. They examined the criticality of friction and damping coefficients [9]. In the dynamic system modelling, Berger set forth that the phenomenon of friction was a pair together with the behaviour of the system and could not be considered independent of each other [10]. Erkaya et al. carried out the analysis of mechanism of the systems on Adams program and compared the results with the tests. They revealed the effect of dynamic friction coefficient on sliding behaviour and examined the effect of the gap on the flexible joint on the dynamic motion [11]. Zheng and Zhou used the Adams program to solve the differential equations of the motion equation of the mechanism. The rigid-flexible pair model of the mechanism of the crank connecting rod was solved by the Adams program and the effect of the gap in the joints on the movement was examined [12]. Patil and Teodoriu solved the mathematical model comprised of non-linear differential equations of torsion boring using Matlab Simulink software [13].

In this study, the equation of motion written analytically is solved by numerical method. The solving of the motion equation is necessary to know the required drive pressure during the deployment of the system and at the same time to determine in what time and at what angle the system is deployed. In the Folded Fin Mechanism, it is the drive pressure-induced torque that allows the fin to be deployed.

Friction and damping directly affect the deployment time and deployment angle of the mechanism and change the dynamic behaviour of the system. In order to solve the equation of motion of the system, firstly Matlab Simulink was used to calculate the drive pressure required to bring the fin to the desired position in the time desired without friction and damping coefficient. Then, the pressure data measured from the tests performed were entered into the Simulink model of the motion equation of the mechanism as time dependent function and the dynamic behaviour of the system was solved. At the same time, the pressure data measured were the load input of the Adams mechanism model. While the pressure data measurements were being made, the deployment of the system was recorded by means of a High-Speed camera at the same time. Santer et al. used the videogrammetric approach for the experimentally determination of dynamic friction coefficient. In line with this approach, they recorded the deployment images of their systems by means of a high speed Phantom V5.1 camera [14].

During the design of the system, load conditions and desired deployment times can change continuously depending on the results of the studies of different disciplines. As testing is not possible for each changing situation in terms of time and cost, a method was developed based on the results obtained from numerical methods in this study.

\section{Numerical Studies}

In order for the dynamic behaviour of a system to be determined, the motion equation of that system first needs to be solved. General motion equation that determines the behaviour of a linear system is as it is in Eq.1 [15].

$$
M \ddot{u}(t)+C \dot{u}(t)+F(u)=R(t)
$$

This equation takes the form in Eq.2 in accordance with the continuous undamped circular motion of the folded fin mechanism.

Where;

$$
\Theta \ddot{\varphi}(t)+M(\varphi)=R(t)
$$

$\boldsymbol{\Theta} \quad$ Circular moment of inertia

$\ddot{\boldsymbol{\varphi}}(\boldsymbol{t}) \quad$ Angular acceleration

$R(t) \quad$ Force applied on system; deployment forces and aerodynamic loads

$M(\varphi) \quad$ Pressure-induced torque provided by pyrotechnic system 
In the deployment tests of the folded fin mechanism, no external force affects the system. Friction and damping acting on the system were not taken into account in the first differential equation solution carried out with Matlab Simulink model (Fig. 1). With the first differential equation solution performed, the drive pressure effect of the enclosed-volume-pressure value of the gas generator was solved by the Simulink model below. This first solution revealed in what time and at what angle the torque provided by the gas generator rotated the system. This solution provided us with insight about the behaviour of the system prior to the test to be carried out.

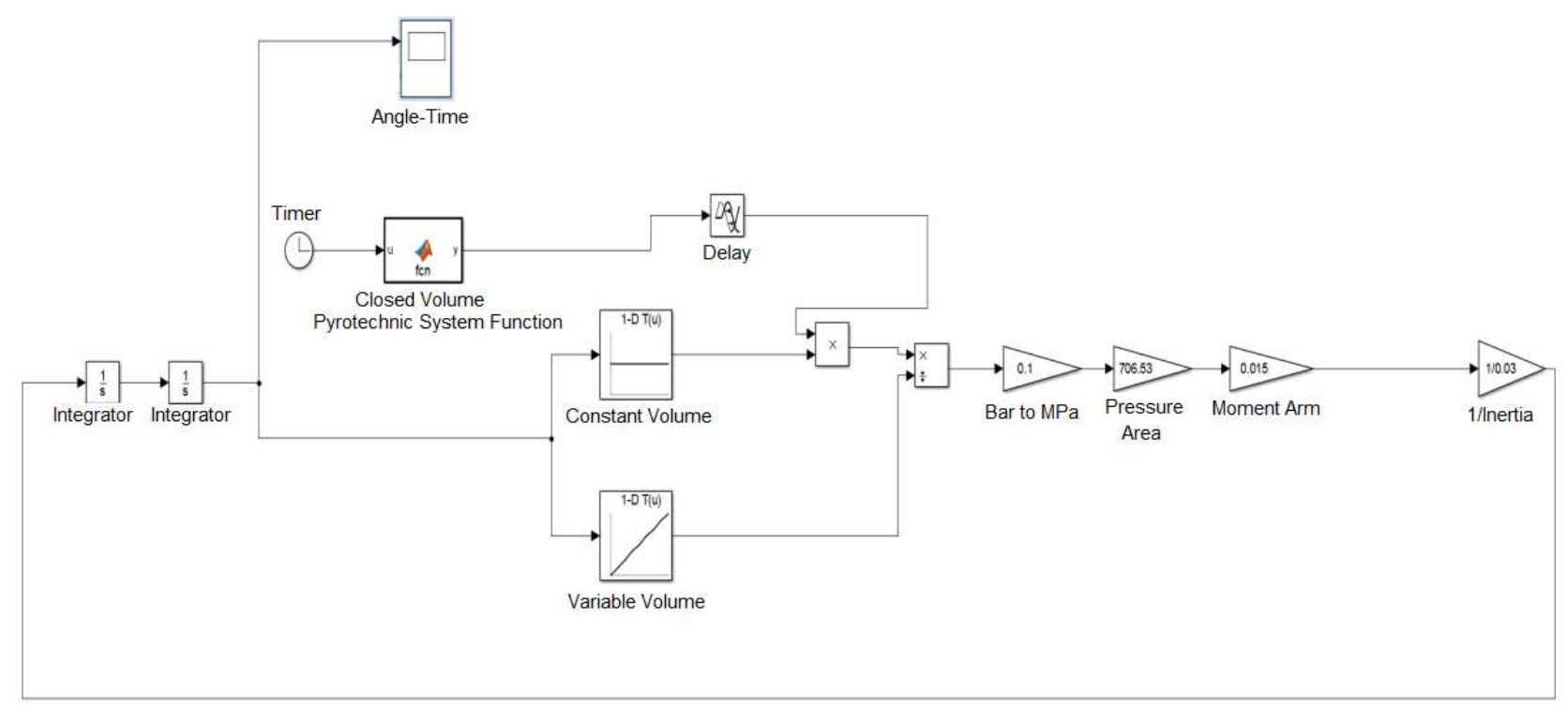

Fig. 1 Detection of Drive Pressure, Matlab Simulink Model

Friction and damping factors have a significant place in the motion of the folded fin mechanism. As the dynamic friction, static friction and damping coefficients were initially not known, so each period was defined using the literature [16]. The DOE module was utilised to solve the equation of motion of the system rigidly in Adams MBD. In this context, four different DOEs were carried out within the scope of Test-C. As seen below Fin deployment angle versus time in Test-C was given in Figure 2.

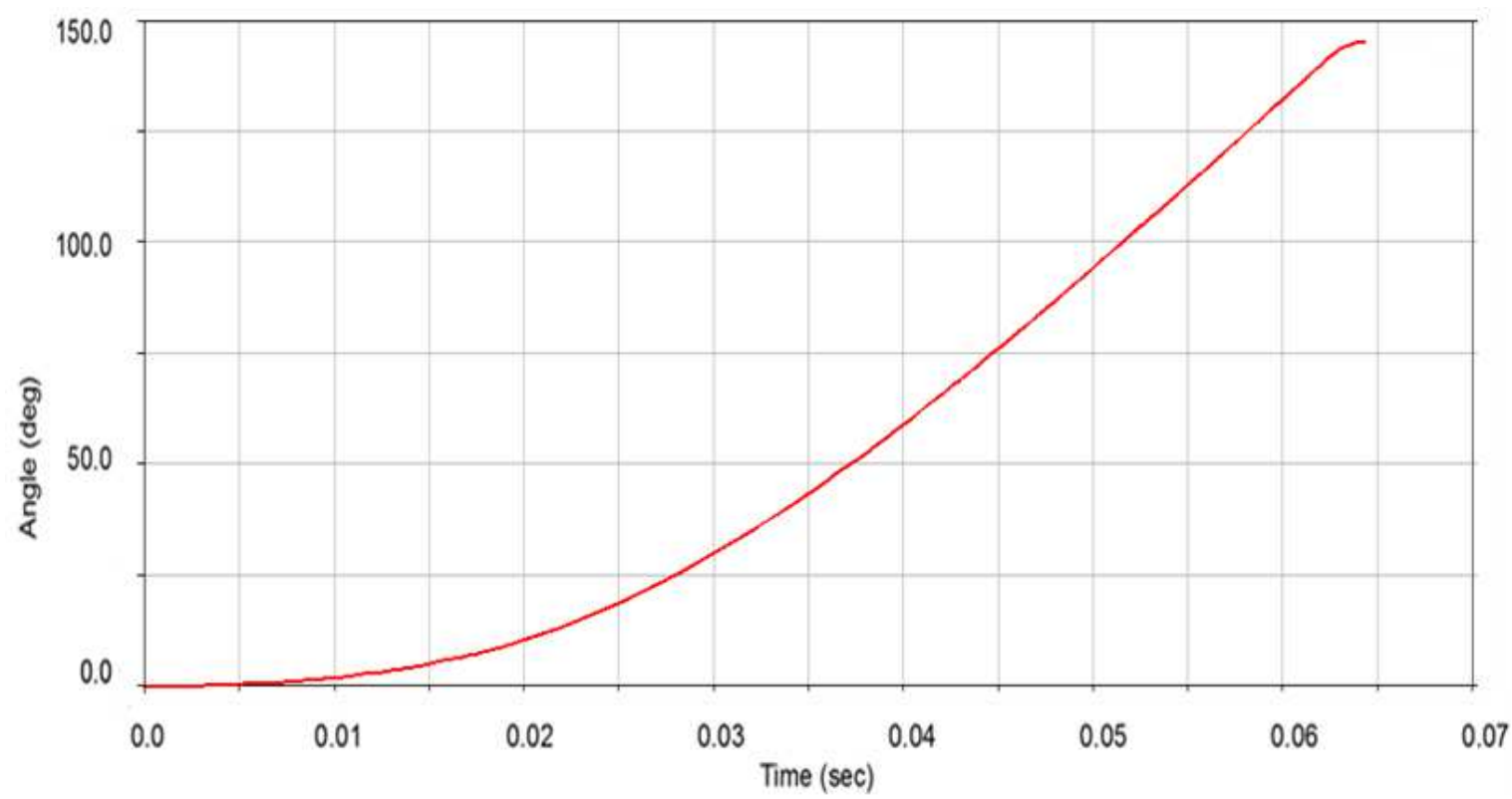

Fig. 2 Test-C Fin deployment angle versus time 
DOE analyses are the ANOVA analyses, which reveal what the effect of the variable parameters of a system on the actual system is and make the mathematical model of the mechanism compatible with experimental data by making linear regression analysis. In this study, it will be possible to understand what factors affect the motion of the mechanism by DOE analysis. By running multiple analyses in accordance with the time and the drive pressure profile taken from the first test of the mechanism conducted, effect of the damping as well as the dynamic and static friction coefficients defined for Test-C on the time-dependent variation of the fin angle was obtained. System characteristics defined for DOE-1 are shown in Table 1.

Table 1 Design Variables of DOE-1

\begin{tabular}{ccc}
\hline & \multicolumn{2}{c}{ DOE-1 Design Variables } \\
Damping Coefficient & Dynamic Friction Coefficient & Static Friction Coefficient \\
\hline 80 & 0.01 & 0.06 \\
140 & 0.105 & 0.18 \\
200 & 0.2 & 0.3 \\
\hline
\end{tabular}

In the DOE-1 analysis, twenty-seven analyses were run consecutively for three different values of the three variables. As can be seen from Fig. 3, the values of the first, second, tenth, eleventh and twentieth analyses, which achieved the desired maximum fin angle, in accordance with the deployment time measured in Test-C were used for DOE-2. As seen in Fig. 3, the effect of the variation of static friction coefficient on the deployment characteristics of the system is less than the other two variables. This situation is due to the fact that the system moves from a stationary state to motion state in a very short period of time and thus the static friction effect is very low. When the results obtained were examined, it was seen that the system was not deployed in the variations having a static friction coefficient of 0.3 .

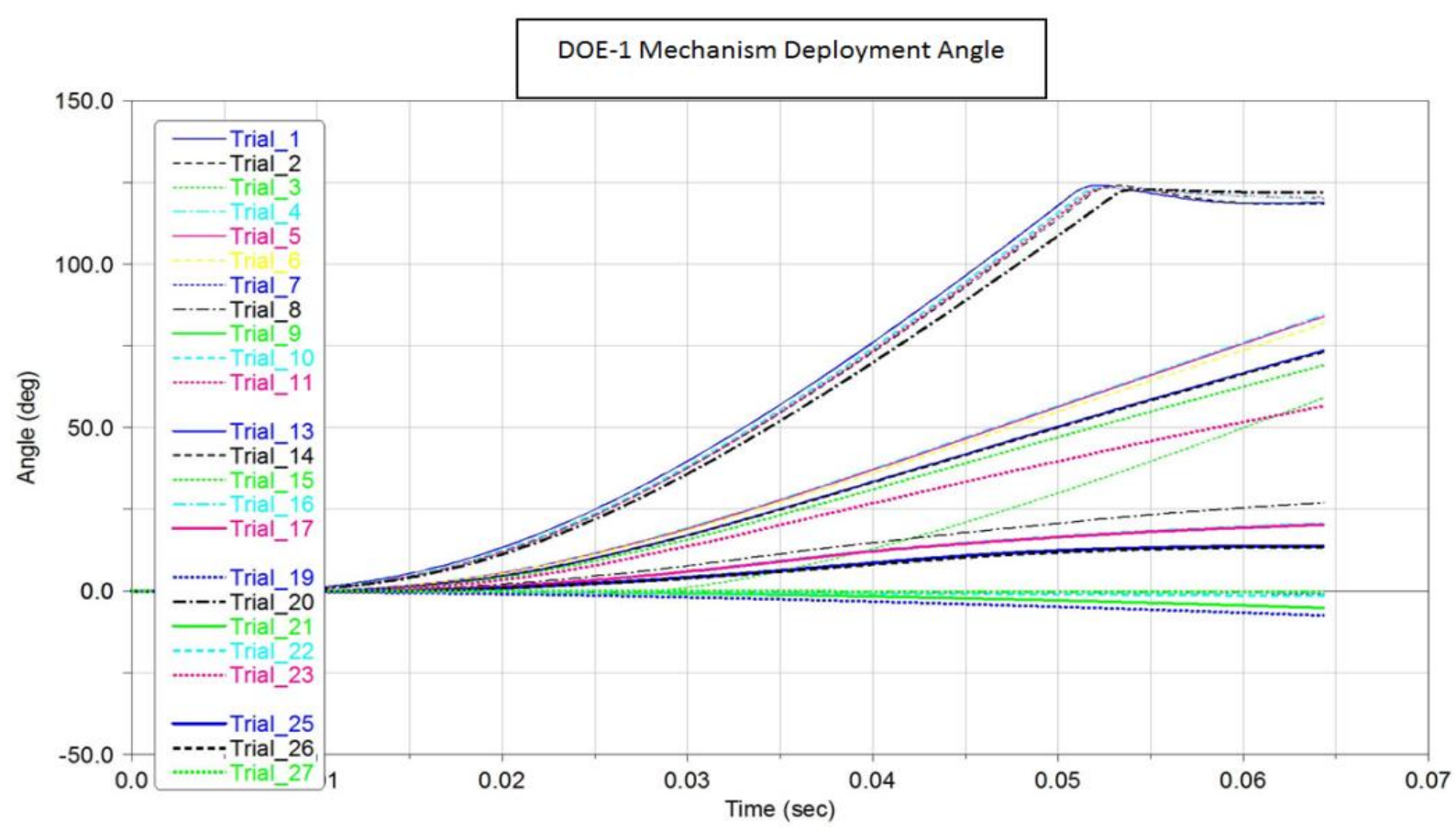

Fig. 3 Comparison of DOE-1 Analyses: Time-dependent variation of deployment angle of mechanism

For the DOE-2 analysis, the values in Table 2 are used. In addition, static friction coefficient was selected as 0.12 and turned into a fixed variable. A total of nine analyses were run for three separate values of two different variables. 
Table 2 Design Variables of DOE-2

\begin{tabular}{ccc}
\hline & $\begin{array}{c}\text { DOE-2 Design Variables } \\
\text { Damping Coefficient }\end{array}$ & Static Friction Coefficient \\
\hline 80 & 0.01 & 0.12 \\
140 & 0.045 & 0.12 \\
200 & 0.08 & 0.12 \\
\hline
\end{tabular}

As seen in Fig. 4, the values in the second and fifth analyses are the closest ones to the values in Test-C. The values in these two analyses will be taken as references for DOE-3.

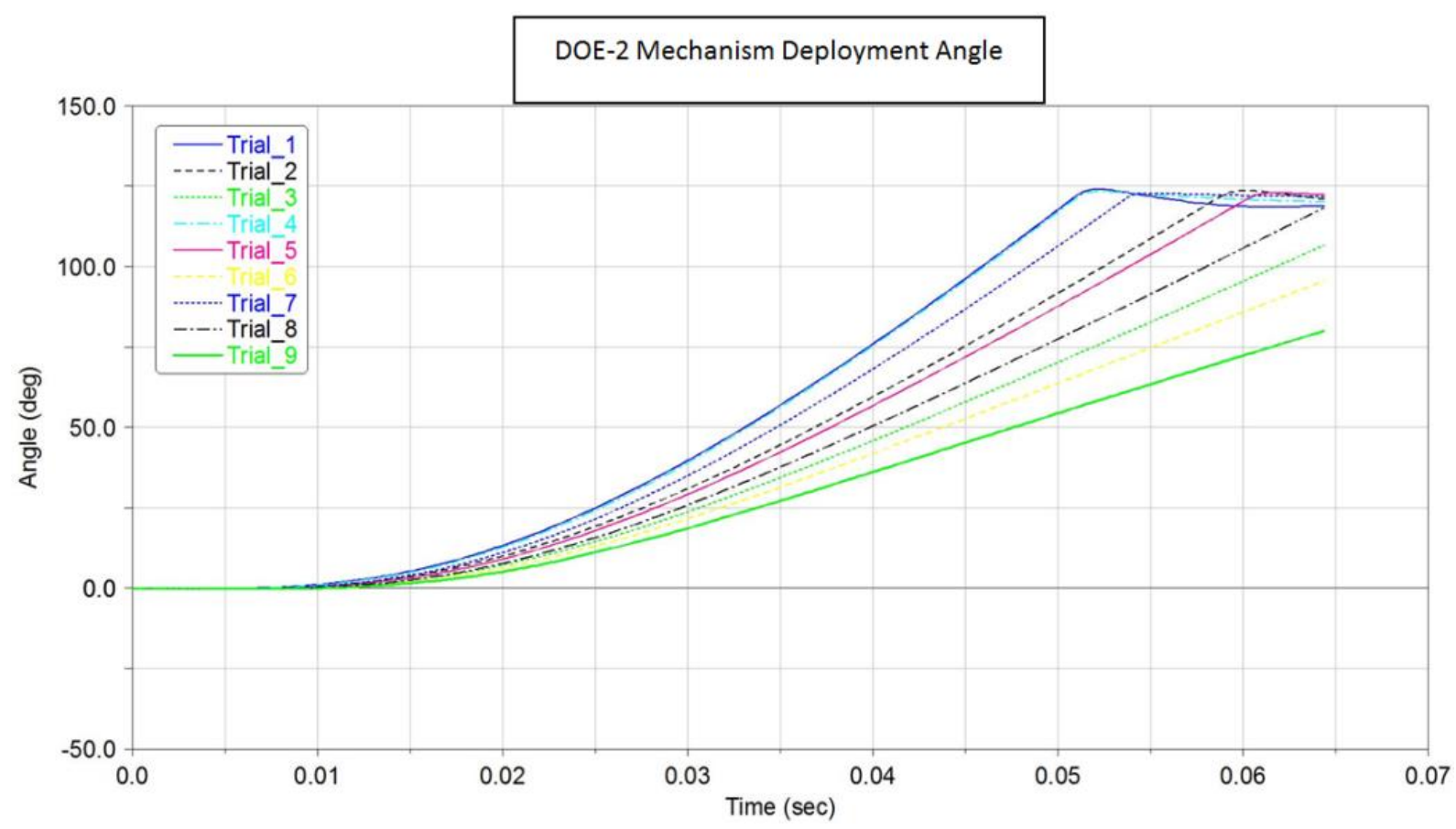

Fig. 4 Comparison of DOE-2 Analyses: Time-dependent variation of deployment angle of mechanism

The variables to be used in DOE-3 are given in Table 3.

Table 3 Design Variables of DOE-3

\begin{tabular}{ccc}
\hline & $\begin{array}{c}\text { DOE-3 Design Variables } \\
\text { Damping Coefficient }\end{array}$ & Static Friction Coefficient \\
\hline 70 & 0.045 & 0.12 \\
135 & 0.0525 & 0.12 \\
200 & 0.06 & 0.12 \\
\hline
\end{tabular}

As seen in Fig. 5, the values in the third and fifth analyses are the closest ones to the values in Test-C. The values in these two analyses will be taken as references for DOE-4. 


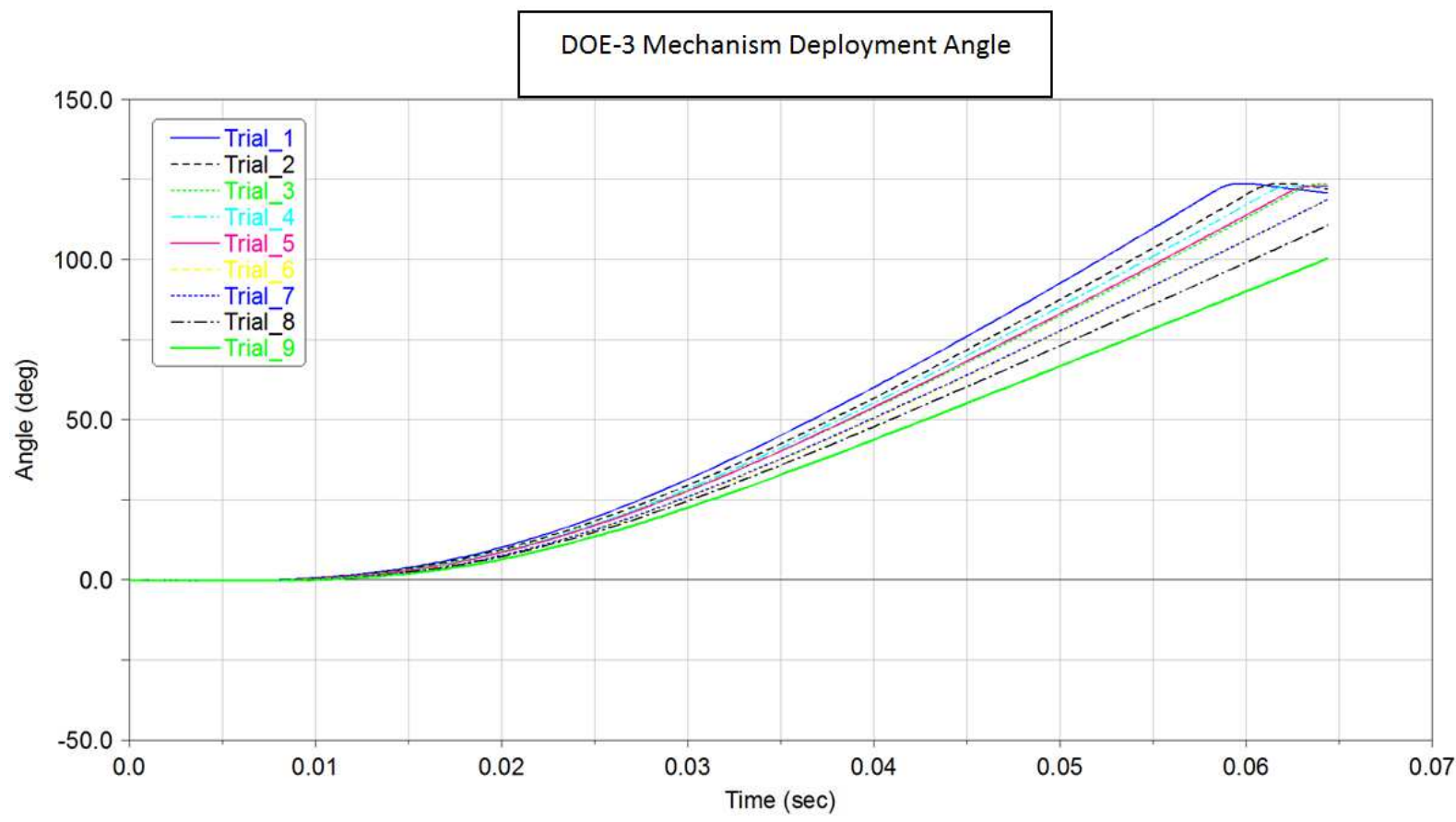

Fig. 5 Comparison of DOE-3 Analyses: Time-dependent variation of deployment angle of mechanism The variables to be used in DOE-4 are given in Table 4 .

Table 4 Design Variables of DOE-4

\begin{tabular}{ccc}
\hline & $\begin{array}{c}\text { DOE-4 Design Variables } \\
\text { Dymamic Friction Coefficient }\end{array}$ & Static Friction Coefficient \\
\hline 68 & 0.0525 & 0.12 \\
100.5 & 0.05625 & 0.12 \\
133 & 0.06 & 0.12 \\
\hline
\end{tabular}

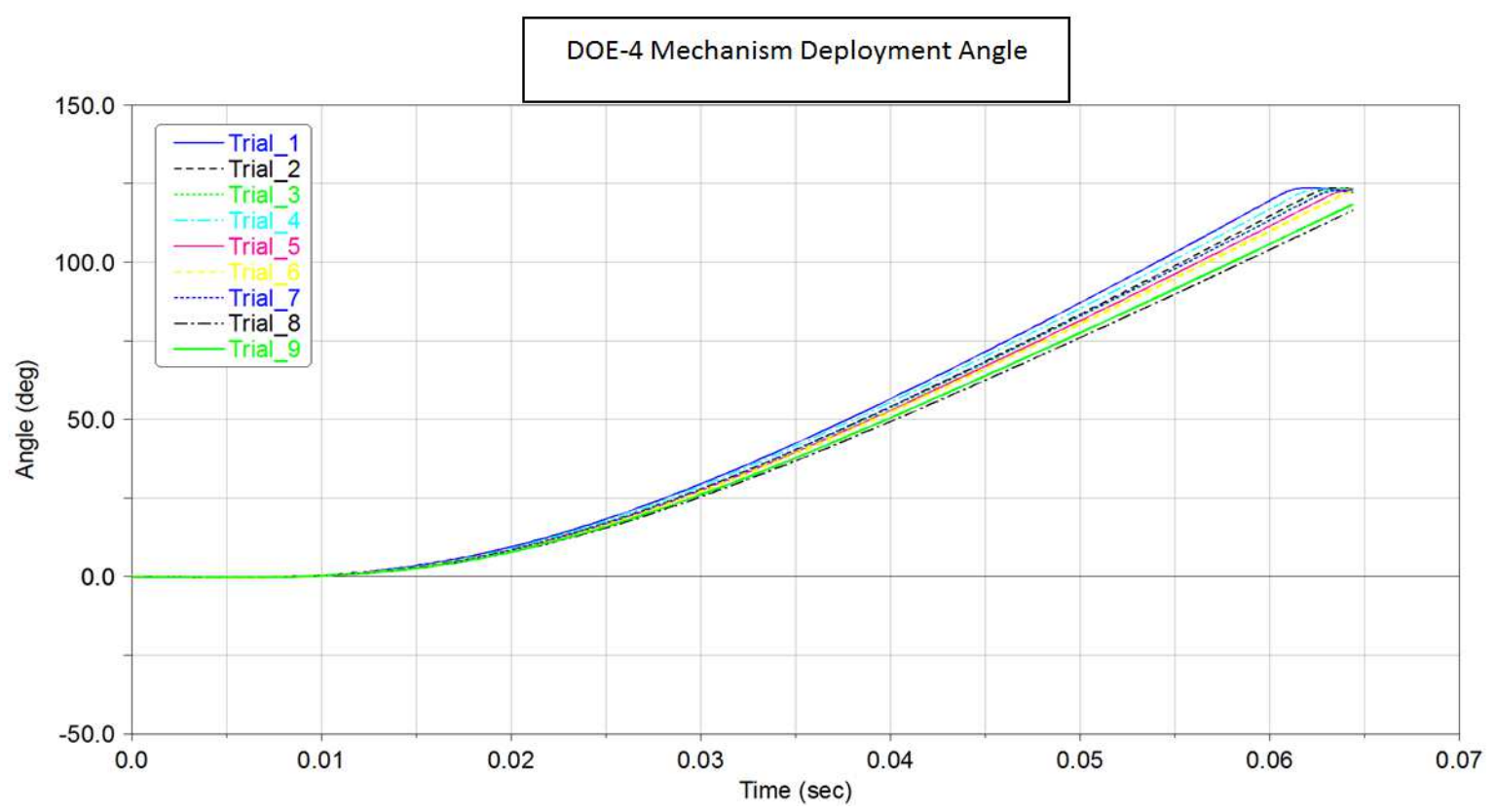

Fig. 6 Comparison of DOE-4 Analyses: Time-dependent variation of deployment angle of mechanism 
As can be seen from Fig. 6, the closest result of the Folded Fin Mechanism in Test-C was obtained in the fifth analysis. Thus, the coefficient of static friction was found to be 0.12 , the coefficient of dynamic friction 0.05625 and the coefficient of extinction 100.5. These coefficients were used in the Adams MBD mechanism models using the pressure data between Test-1 and Test-13. The pressure data taken from the tests were repeated for each test in the Matlab Simulink model shown in Fig. 7 in accordance with Test-C and the deployment angles and durations of the folded fin mechanism were determined.

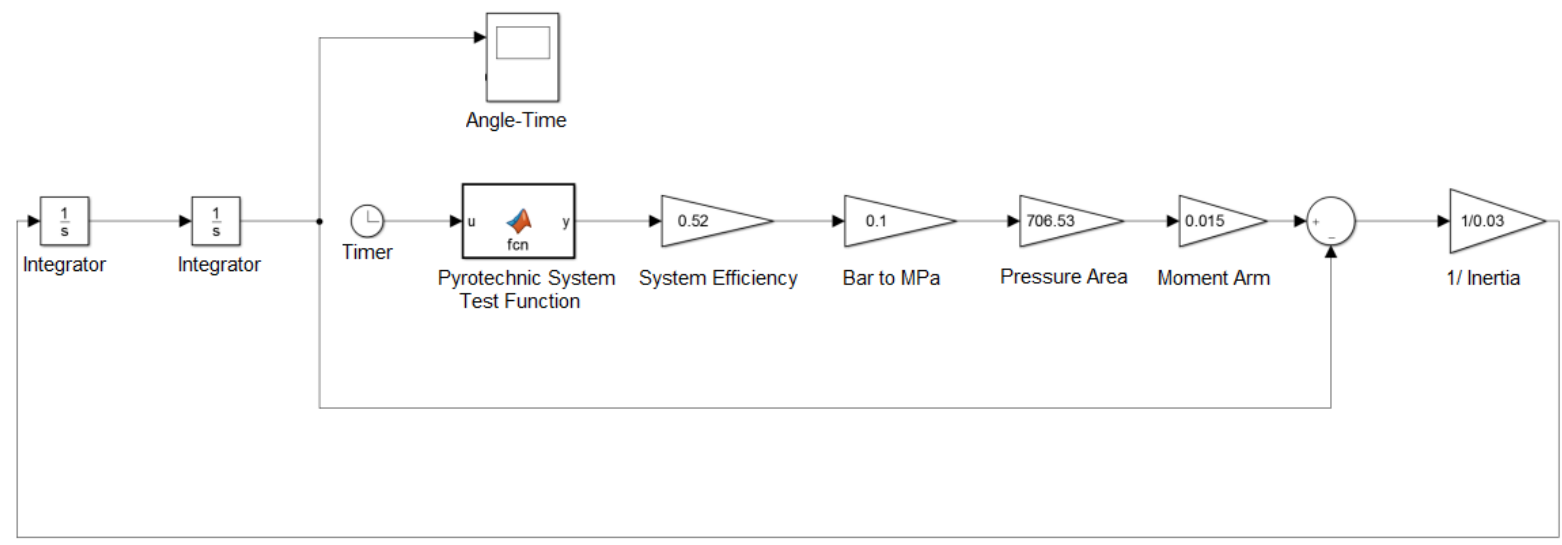

Fig. 7 Matlab Simulink Model of the Mechanism

\section{Experimental Studies}

The data of the enclosed-volume drive pressure used in the thirteen separate tests performed are given in Table 5. During the dynamic motion of the mechanism, these pressure values vary as shown in Fig. 8, depending on the volume at which the drive pressure is affected.

Table 5 Enclosed Volume and Test Pressure Values

Maximum Pressure Values of 100cc Enclosed Volume (Bar)

\begin{tabular}{cc}
\hline Test Number & Pressure (bar) \\
\hline 1 & 15 \\
2 & 25 \\
3 & 30 \\
4 & 35 \\
5 & 40 \\
6 & 45 \\
7 & 50 \\
8 & 55 \\
9 & 60 \\
10 & 65 \\
11 & 70 \\
12 & 75 \\
13 & 80
\end{tabular}




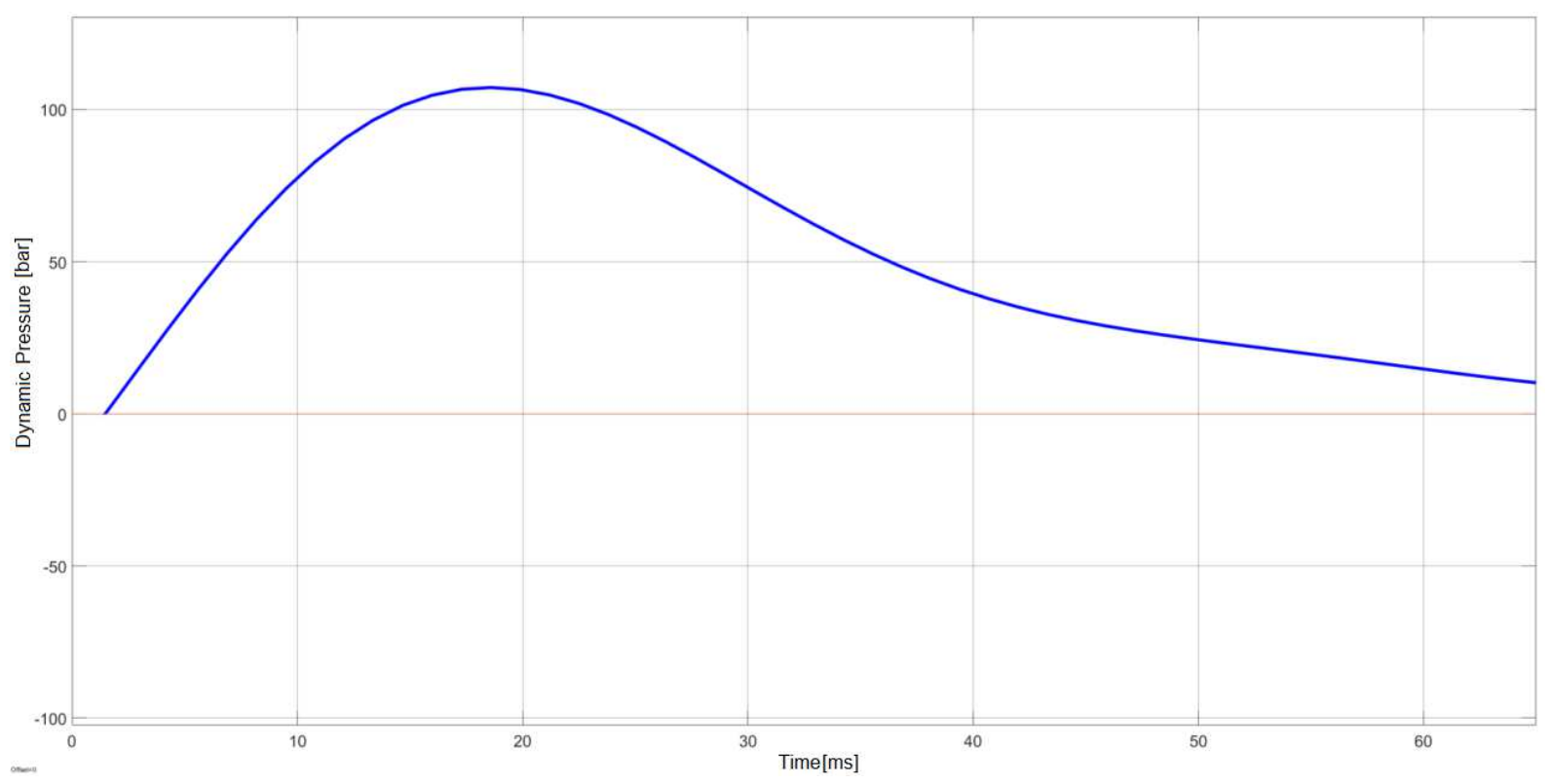

Fig. 8 Test-C Pressure Graph of Dynamic State

Deployment test assembly of the folded fin mechanism is shown in Fig. 9. In the test setup, the drive pressure data and the system's deployment motion were recorded momentarily during the test. Pressure data and high-speed camera images were taken from three separate deployment tests. The pressure data obtained formed the inputs of the Adams and Matlab Simulink mechanism models.

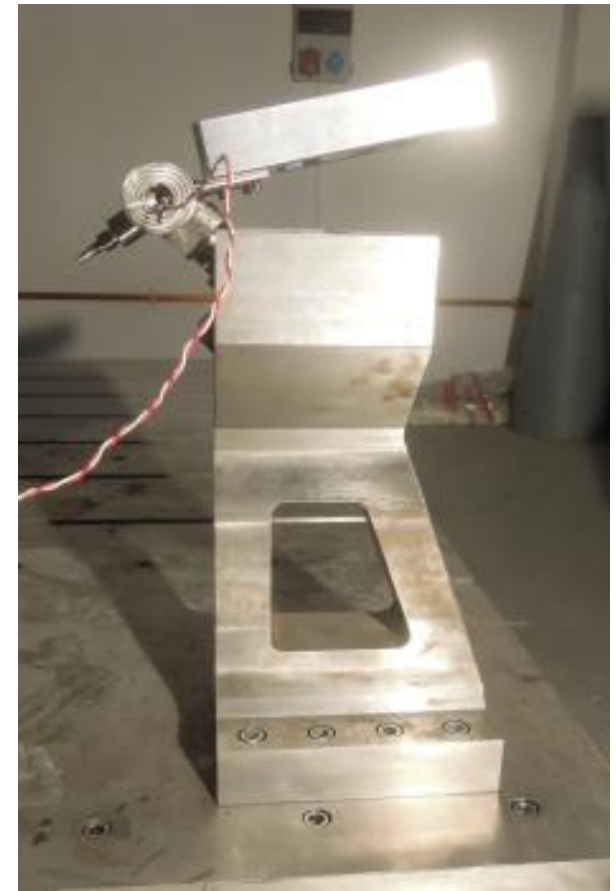

(a) Closed State

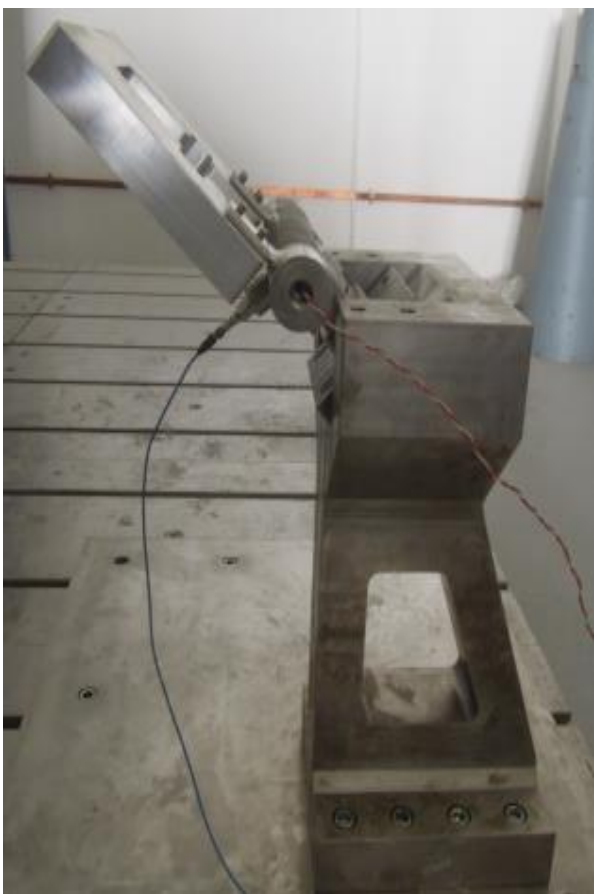

(b) Deployed State

Fig.9 Views of Test Setup for Folded Fin Mechanism

\section{Results and Discussions}

Experimental studies carried out in order to test the performance of the fin deployment system. Image of Adams analysis and high-speed camera images correlated with Test are shown in Fig. 10. 


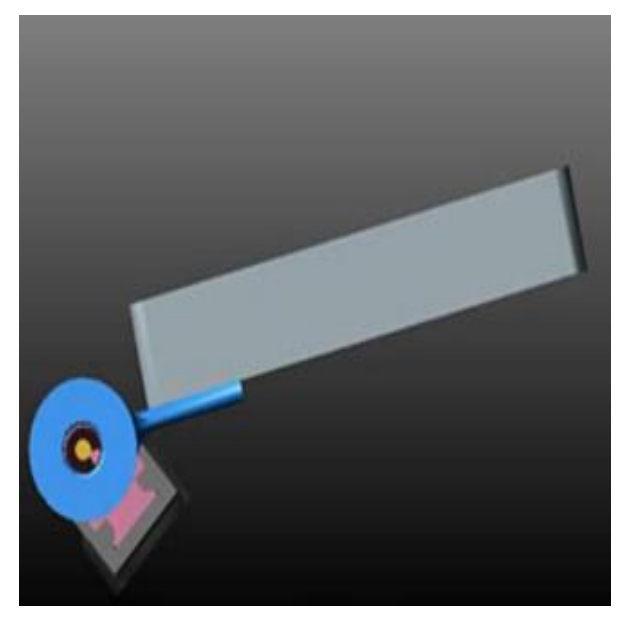

(a) Initial Position of System - Adams Analysis

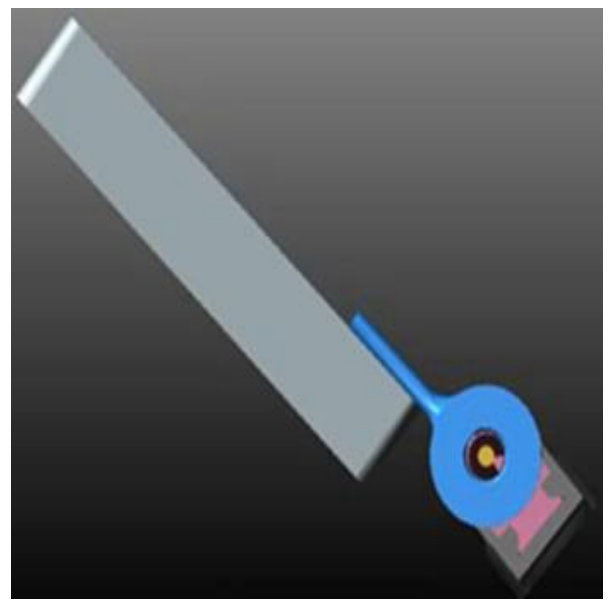

(c) Final Position of System - Adams Analysis

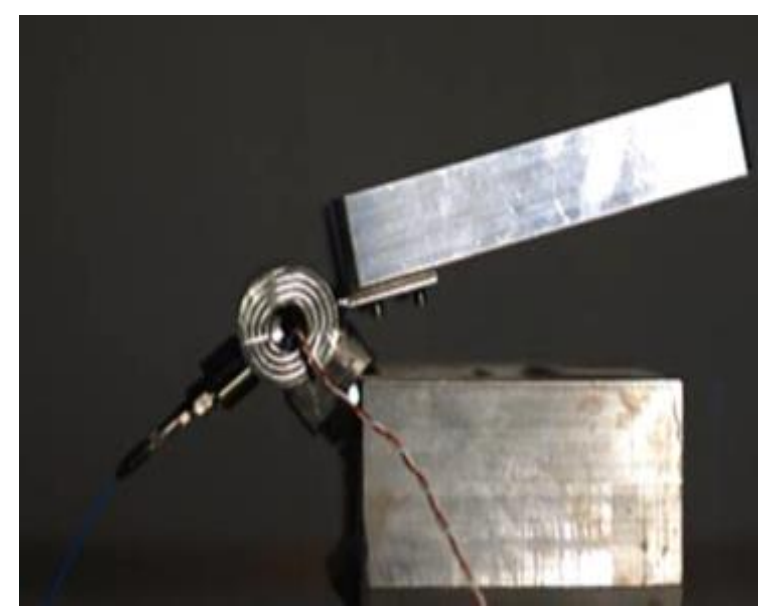

(b) Initial Position of System - Test

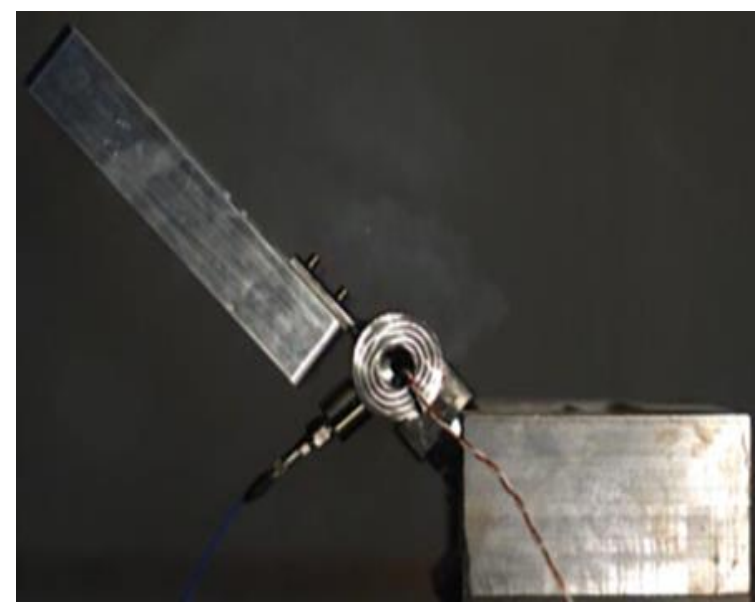

(d) Final Position of System - Test

Fig. 10 Deployment images of Test-C and Adams Analysis

The fin deployment times of different samples for Simulink Model, Adams Analysis Model and Test Results, are given in Table 6. The percentage deviations between Adams Model and Test Results are 2.67\% and 3.36\% for Simulink Model and Test Results, respectively. The reason for these small differences may be noise, solution methods and unspecified losses.

Table 6 System deployment times at Maximum deployment angle of Mechanism

\begin{tabular}{ccccc} 
Sample Number & Pressure (bar) & Simulink Time(s) & Adams Time(s) & Test Time(s) \\
\hline 1 & 15 & 77.4 & 77.9 & 81.0 \\
2 & 25 & 56.5 & 58.3 & 59.1 \\
3 & 30 & 51.1 & 52.5 & 53.2 \\
4 & 35 & 47.0 & 46.2 & 45.1 \\
5 & 40 & 44.0 & 45.0 & 44.5 \\
6 & 45 & 41.5 & 41.9 & 43.9 \\
7 & 50 & 39.5 & 40.2 & 39.0 \\
8 & 55 & 37.8 & 38.5 & 38.2 \\
9 & 60 & 36.3 & 36.8 & 38.4 \\
10 & 65 & 35.1 & 35.4 & 37.2 \\
11 & 70 & 33.9 & 34.2 & 33.2 \\
12 & 75 & 32.9 & 32.6 & 32.5 \\
13 & 80 & 32.0 & 32.2 & 31.0
\end{tabular}


Figure 11a presents Simulink model and Test Results, and Figure 11b presents the comparison of fin deployment times between Adams Analysis and Test Results, also.

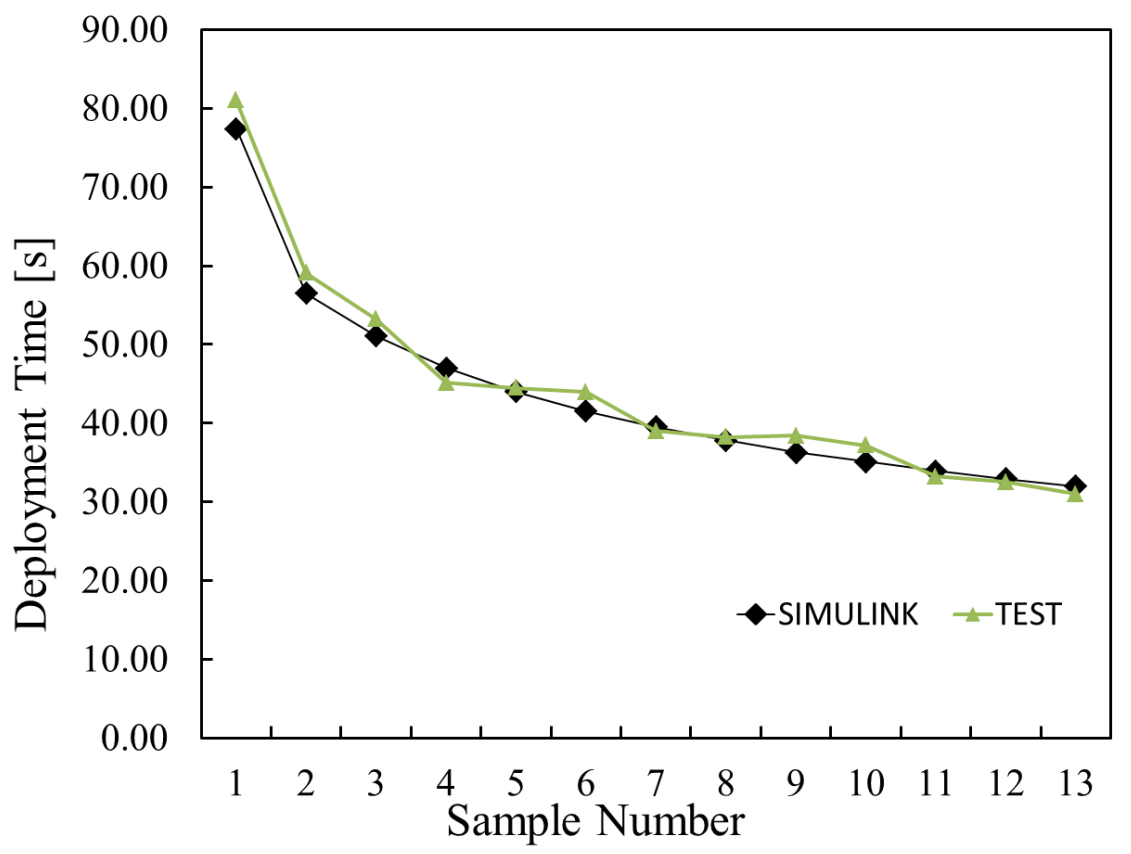

(a)

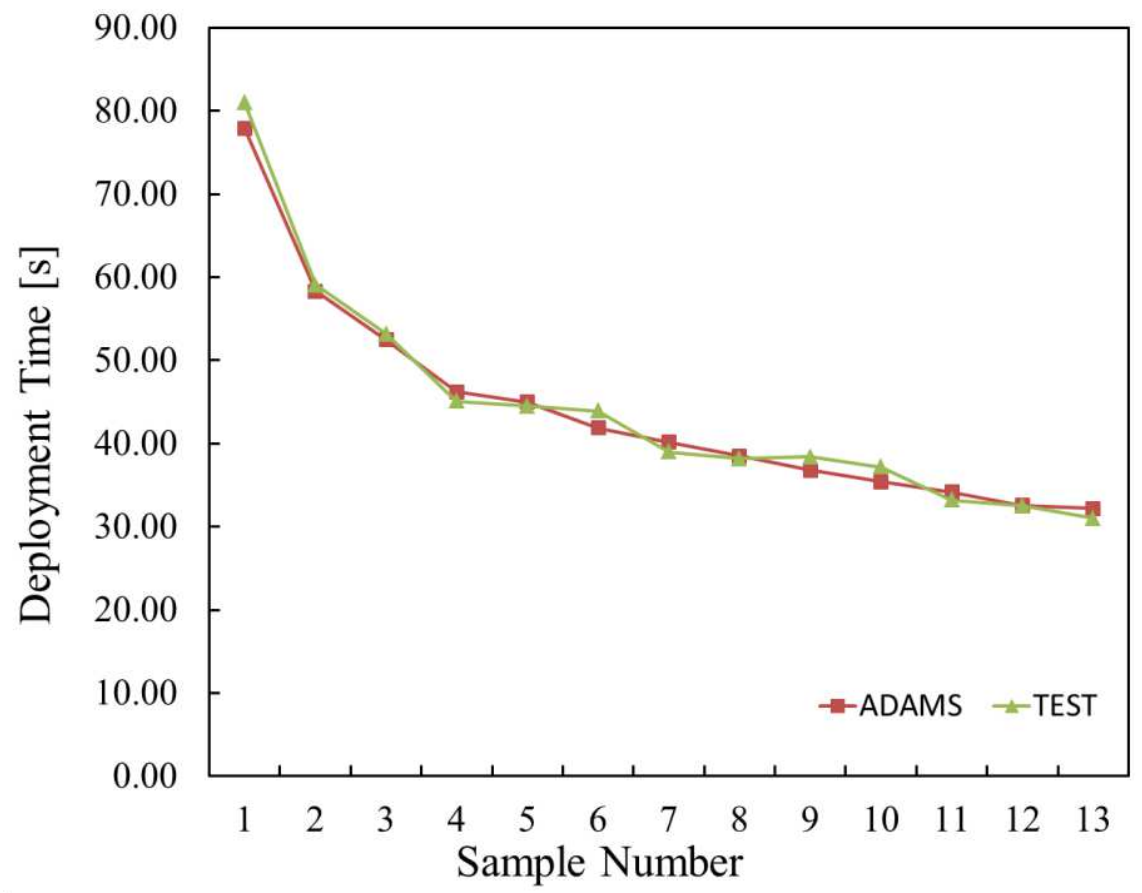

(b)

Fig. 11 Comparison of deployment times of (a) Simulink Model and Test Results (b) Adams Analysis and Test Results 
Adams analysis and Matlab Simulink model correlated in accordance with Test Results and the results in Table 6 and Figure 11 were obtained. When the system drive pressure is increased, the system start time is shortened as expected. Matlab Simulink results are significant as they allow us to provide foresight in terms of system behaviour, but is different from test data based on the results of Adams Analysis.

\section{Conclusions}

Based on the Adams DOE model, which has the highest correlation with the measurement results obtained from Test-C, friction and damping values were obtained. The same mechanism was tested with different drive pressures and the measurement results were compared with the numerical models formed with the design variables determined in Test-C. Compared to the data from the Test- 1 and Test-13 and Adams Mechanism models, the error rate did not exceed $3.4 \%$. It was decided that the friction and damping values determined as a result of the comparison could be used in future numerical analyses.

\section{Ethics Declarations}

\section{Availability of data and materials}

The data that support the findings of this study are available from TUBITAK SAGE but restrictions apply to the availability of these data, which were used under license for the current study, and so are not publicly available. Data are however available from the authors upon reasonable request and with permission of TUBITAK SAGE.

\section{Competing interests}

The authors declare that they have no competing interests.

\section{Funding}

Not Applicable

\section{Authors' contributions}

MA designed folded fin mechanism also carried out test studies, OT helped to numerical studies and was a major contributor in writing the manuscript. OK guided for working methods and testing system. All authors read and approved the final manuscript.

\section{Acknowledgement}

Authors wish to thank TUBITAK SAGE for their motivation, equipment support and the workforce in carrying out this study.

\section{References}

[1]. Fragnito M, Pastena M (2000) Design of smart microsatellite deployable solar wings. Acta Astronautica, 46(2-6):335-344.

[2]. Nagaraj BP, Nataraju BS (1997) Dynamics of a two-link flexible system undergoing locking: Mathematical modelling and comparison with experiments. Journal of Sound and Vibration, 207(4): 567589.

[3]. Gu W, LU M, LIU J, Dong Q, Wang Z, Chen J (2014) Simulation and experimental research on line throwing rocket with flight. Defence Technology, 10:149-153.

[4]. Tiwari N, Patil M, Shankar R, Saraswat A, Dwivedi R (2016) Rigid body dynamics modelling, experimental characterization, and performance analysis of a howitzer. Defence Technology, 12:480-489. 
[5]. Tian Y, Liu M, Xu X (2015) Dynamic simulation analysis on slider-crank mechanism of the mechatronics fitness and entertainment machine based on ADAMS. Applied Mechanics and Materials, 713-715:213-216.

[6]. Wie B, Furumoto N, Banerjee AK, Barbas PM (1986) Modelling and simulation of spacecraft solar array deployment. Journal of Guidance, Control and Dynamics, 9(5):593-598.

[7]. Soykasap O (2009) Deployment analysis of a self-deployable composite boom. Composite Structures, 89:374-381.

[8]. Okuizumi N, Yamamoto T (2009) Centrifugal deployment of membrane with spiral folding: Experiment and simulation. Journal of Space Engineering, 2(1).

[9]. Brusa E, Lemma L (2009) Numerical and experimental analysis of the dynamic effects in compact cluster mills for cold rolling. Journal of Materials Proccessing Technology, 209:2436-2445.

[10]. Berger EJ (2002) Friction modelling for dynamic system simulation. ASME 55(6).

[11]. Erkaya S, Dogan S, Ulus S (2015) Effects of joint clearance on the dynamics of a partly compliant mechanism: Numerical and experimental studies. Mechanism and Machine Theory, 88:125-140.

[12]. Zheng E, Zhou X (2014) Modelling and simulation of flexible slider-crank mechanism with clearance for a closed high speed press system. Mechanism and Machine Theory, 74:10-30.

[13]. Patil PA, Teodoriu C (2013) Model development of torsional drillstring and investigating parametrically the stick-slips influencing factors. Journal of Energy Resources Technology, 135:013103013107.

[14]. Santer M, Sim A, Stafford J (2011) Testing of a segmented compliant deployable boom for cubesat magnetometer missions. 52nd AIAA Structures, Structural Dynamics and Materials Conference.

[15]. Kroyer R (1999) Wing mechanism analysis. Computers and Structures, 72:253-265.

[16]. Giesbers J (2012) Contact mechanics in MSC Adams. Dissertation, University of Twente 
Figures

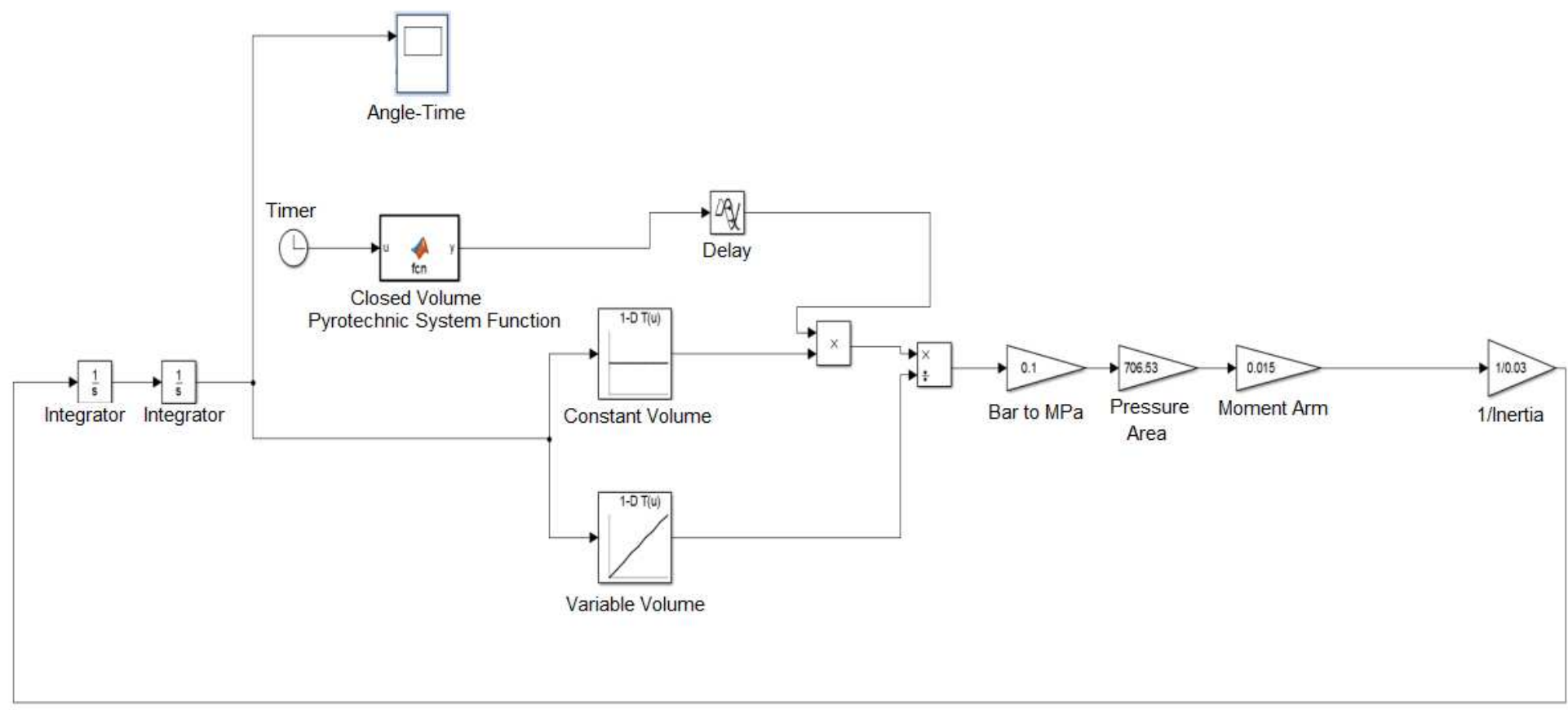

Figure 1

Detection of Drive Pressure, Matlab Simulink Model

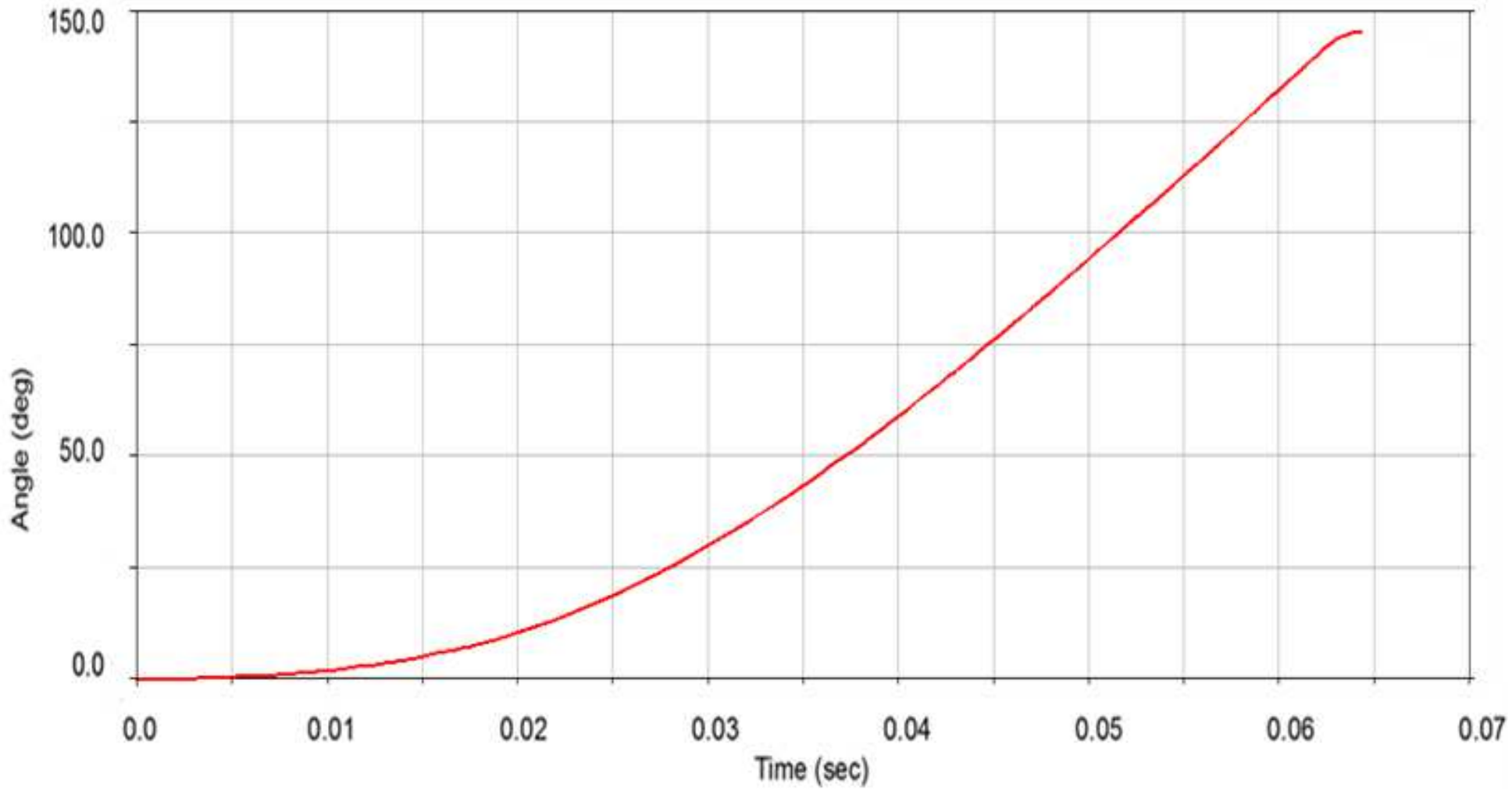

Figure 2 
Test-C Fin deployment angle versus time

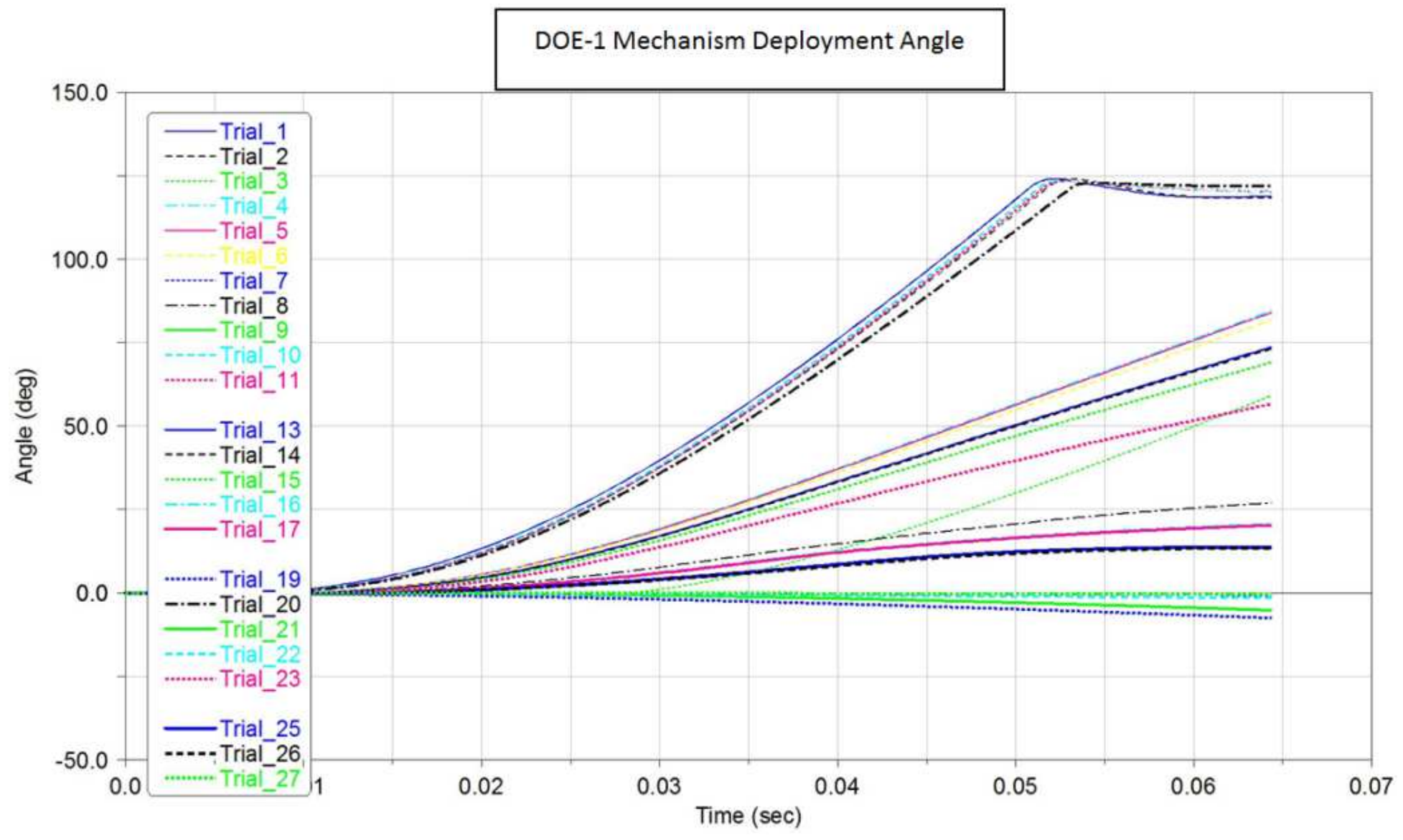

\section{Figure 3}

Comparison of DOE-1 Analyses: Time-dependent variation of deployment angle of mechanism 


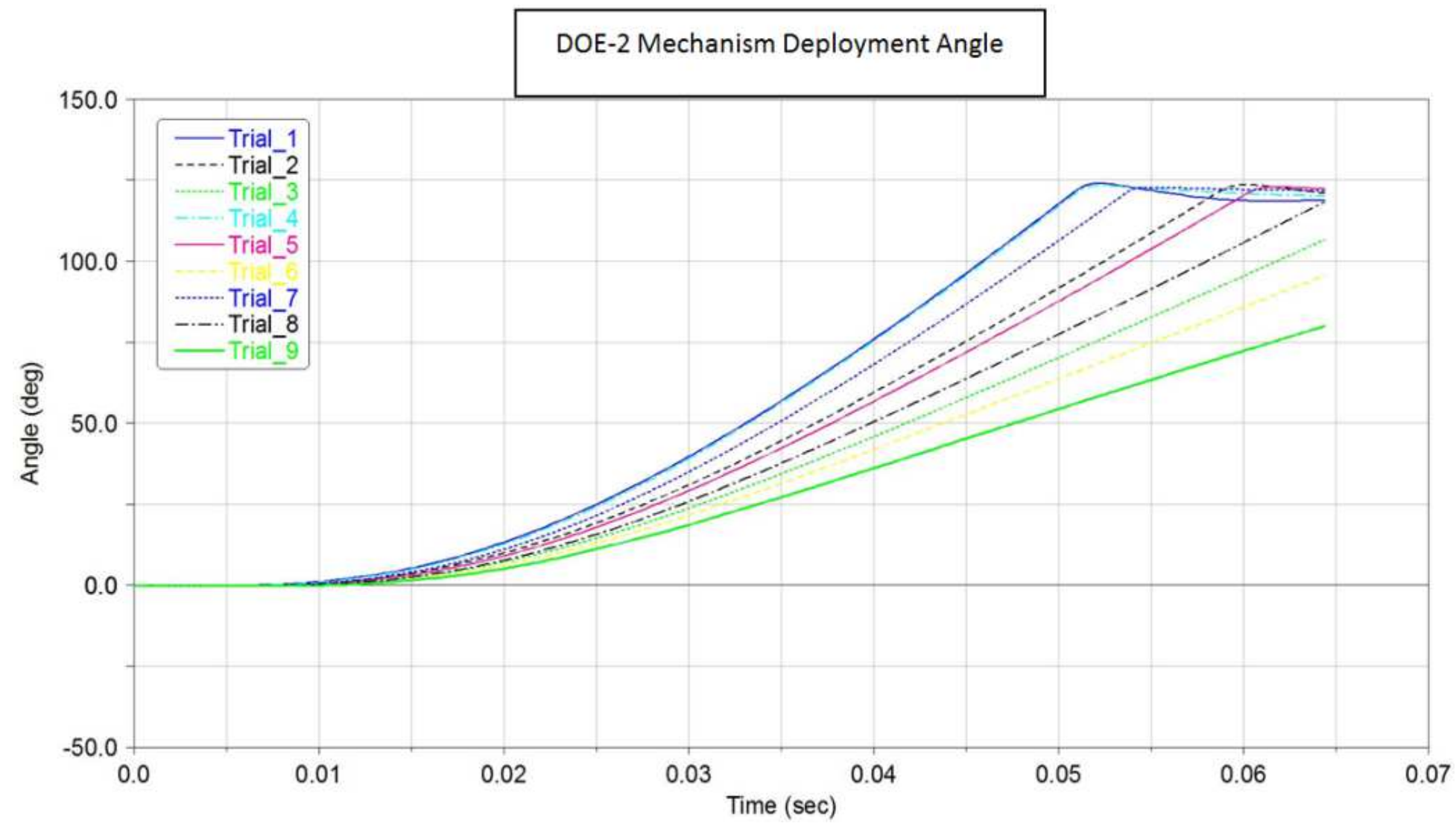

Figure 4

Comparison of DOE-2 Analyses: Time-dependent variation of deployment angle of mechanism.

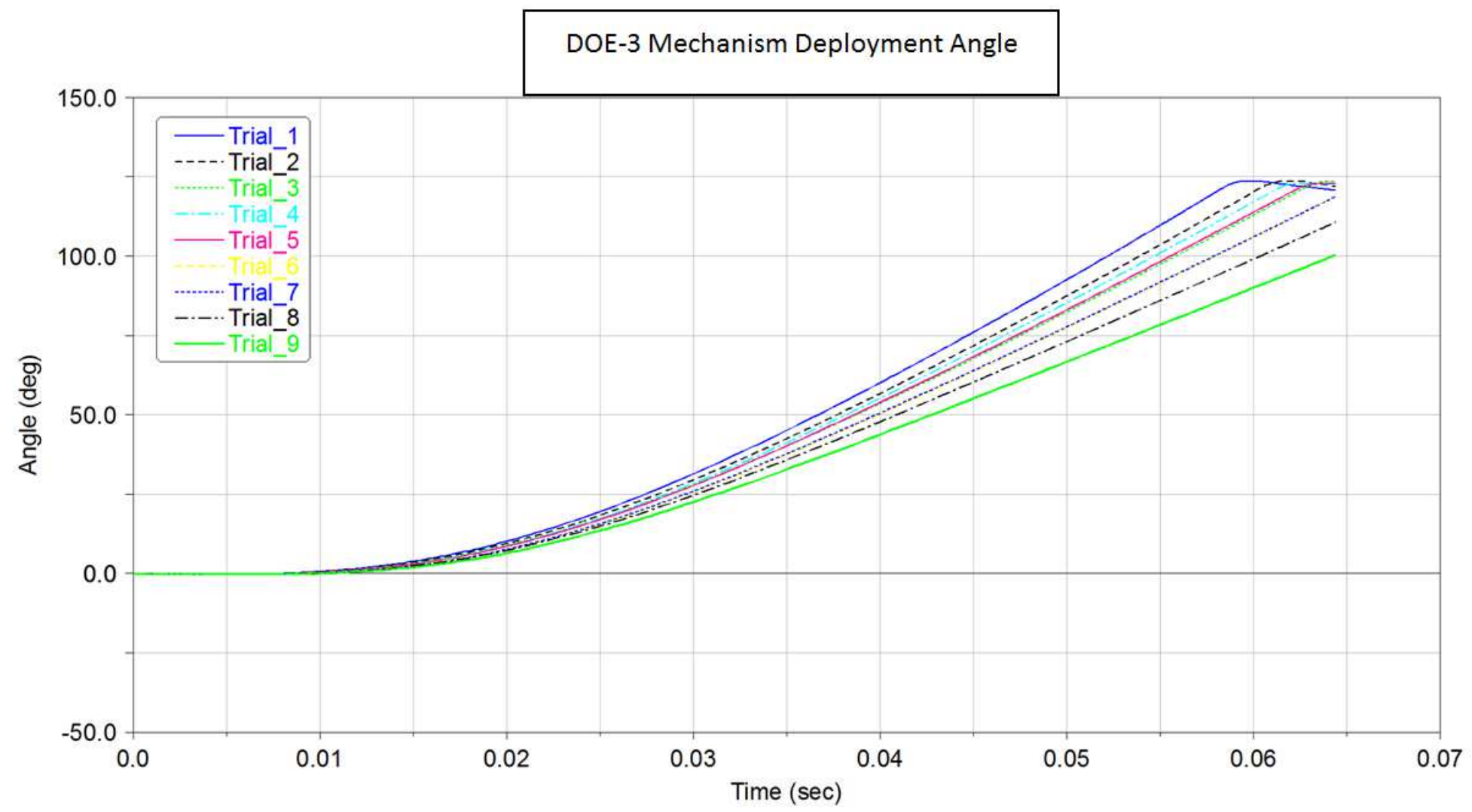

Figure 5 
Comparison of DOE-3 Analyses: Time-dependent variation of deployment angle of mechanism

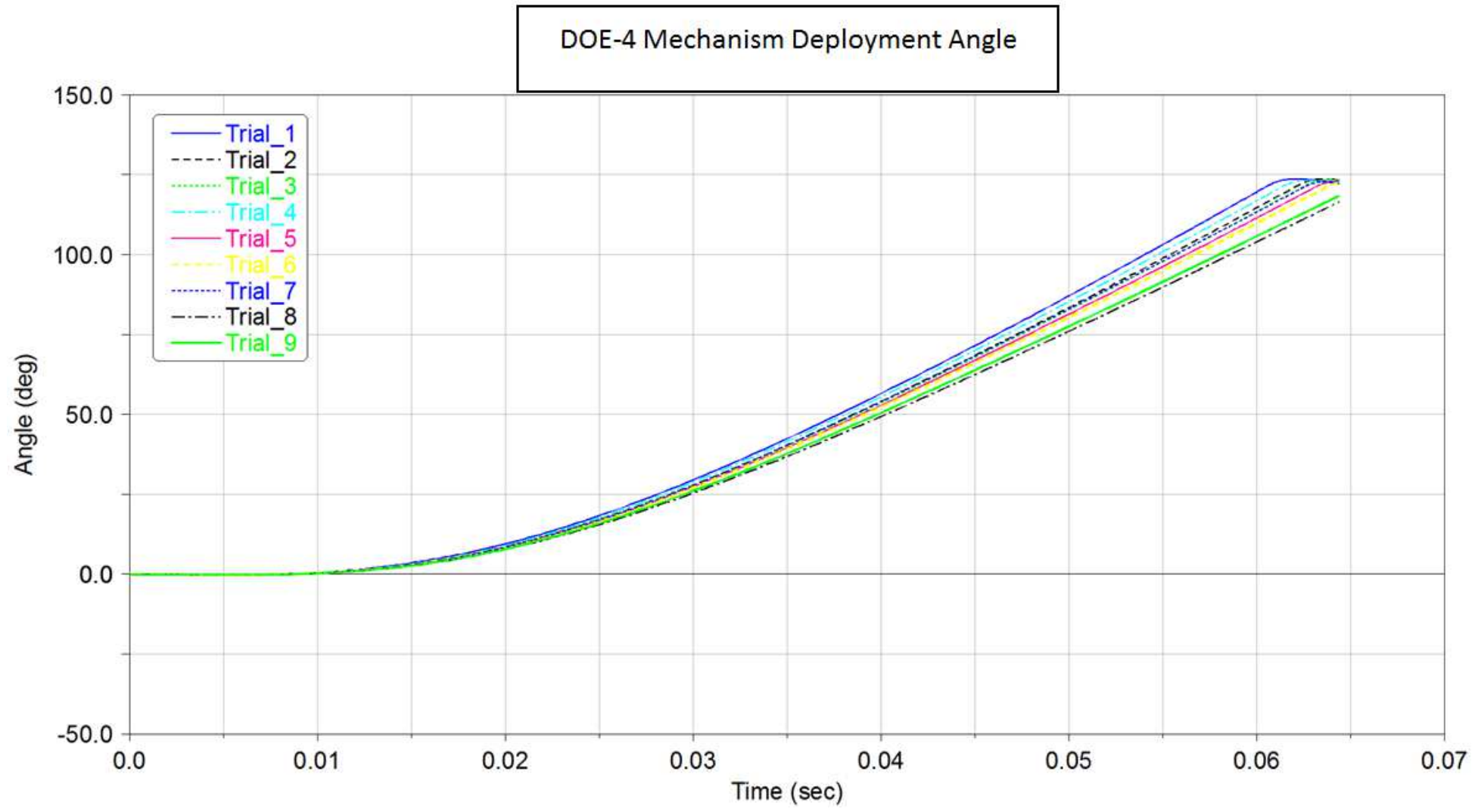

Figure 6

Comparison of DOE-4 Analyses: Time-dependent variation of deployment angle of mechanism

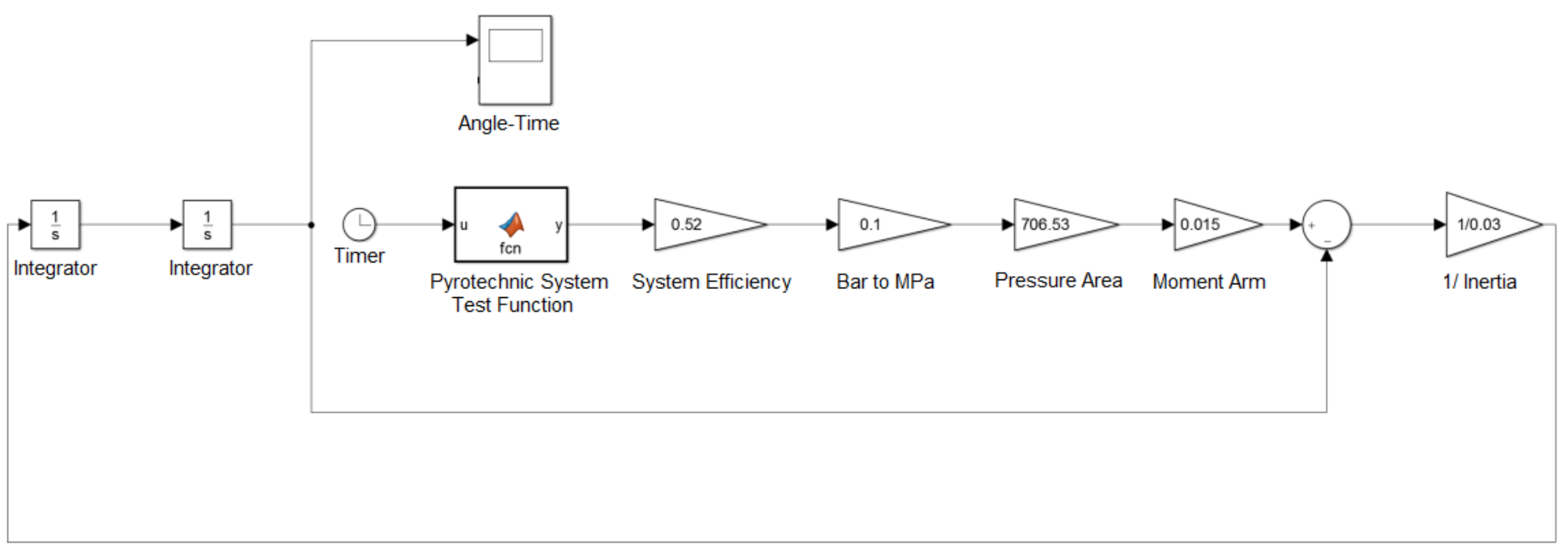

\section{Figure 7}

Matlab Simulink Model of the Mechanism 


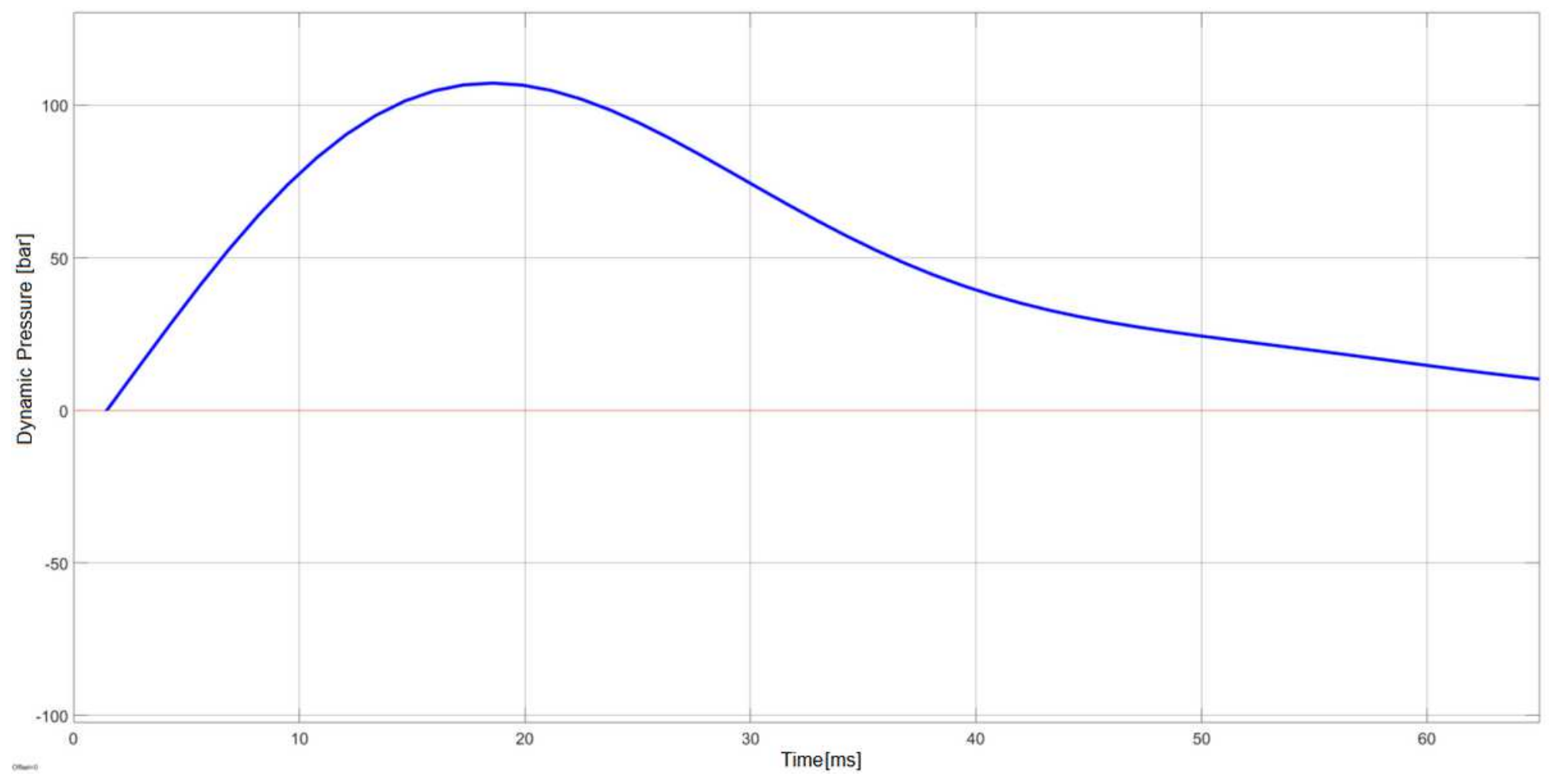

Figure 8

Test-C Pressure Graph of Dynamic State 


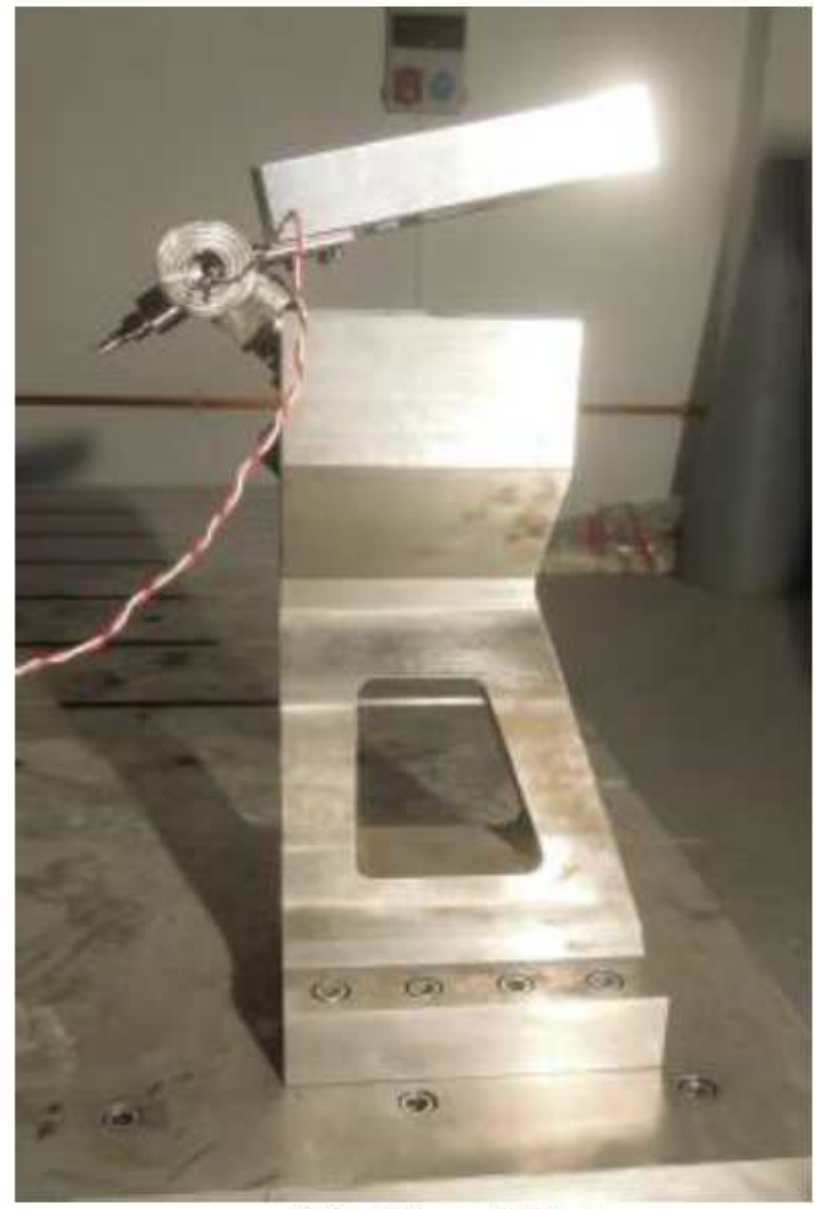

(a) Closed State

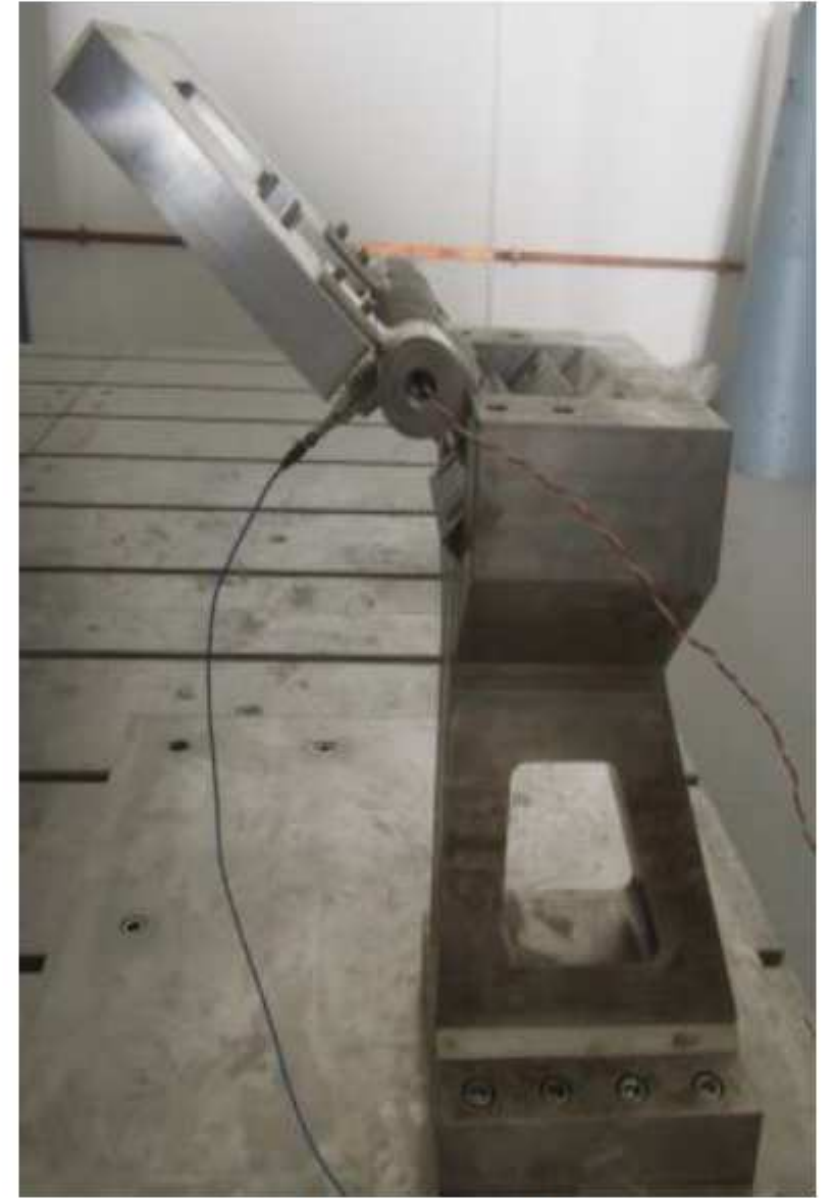

(b) Deployed State

Fig.9 Views of Test Setup for Folded Fin Mechanism

Figure 9

Views of Test Setup for Folded Fin Mechanism 


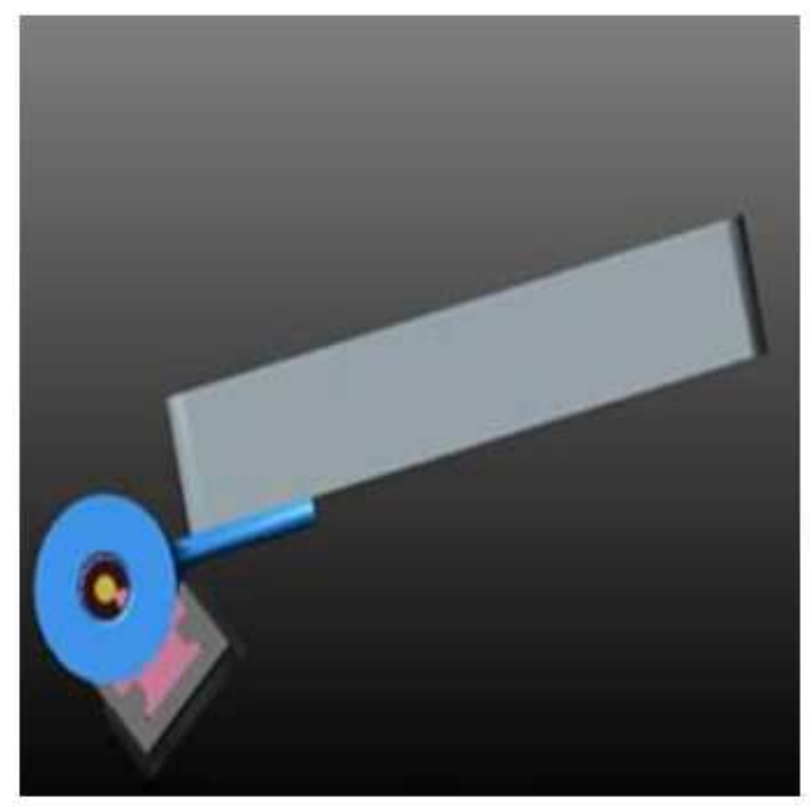

(a) Initial Position of System - Adams Analysis

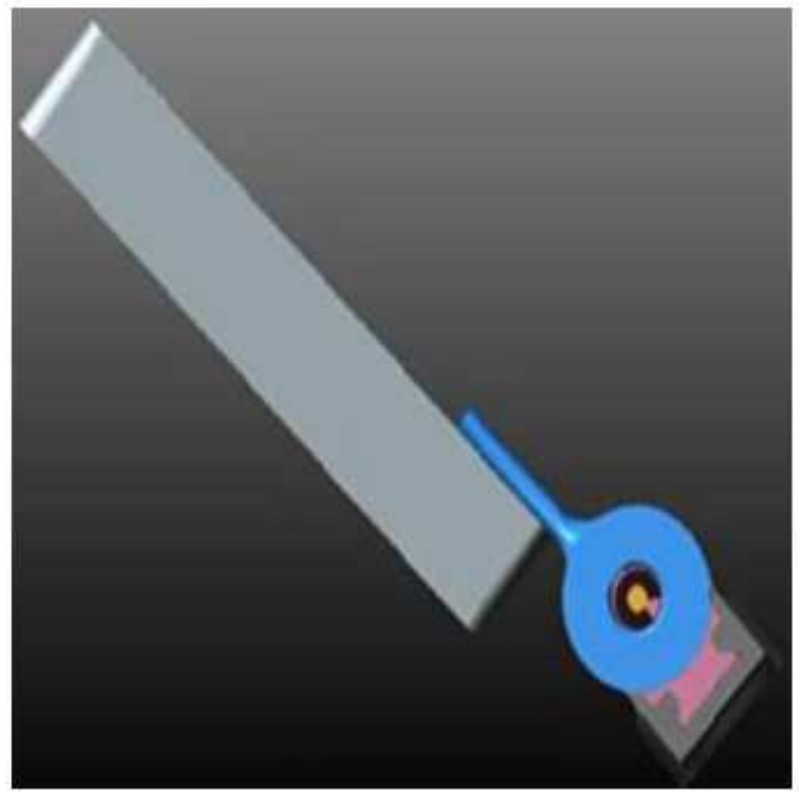

(c) Final Position of System - Adams Analysis

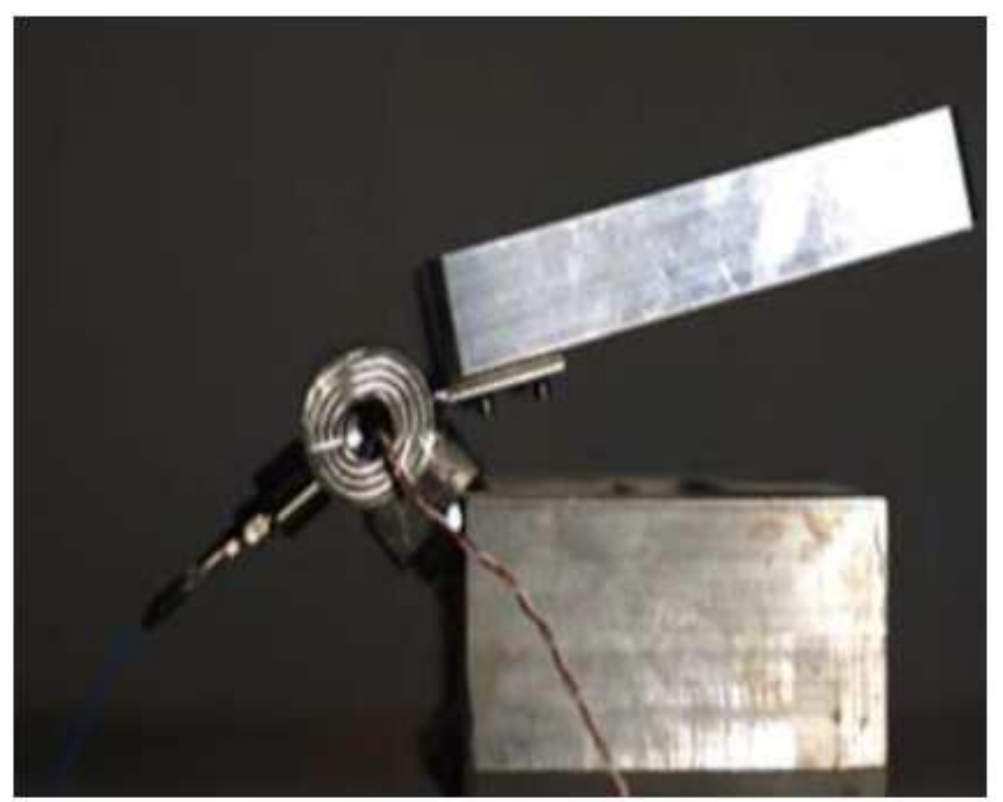

(b) Initial Position of System - Test

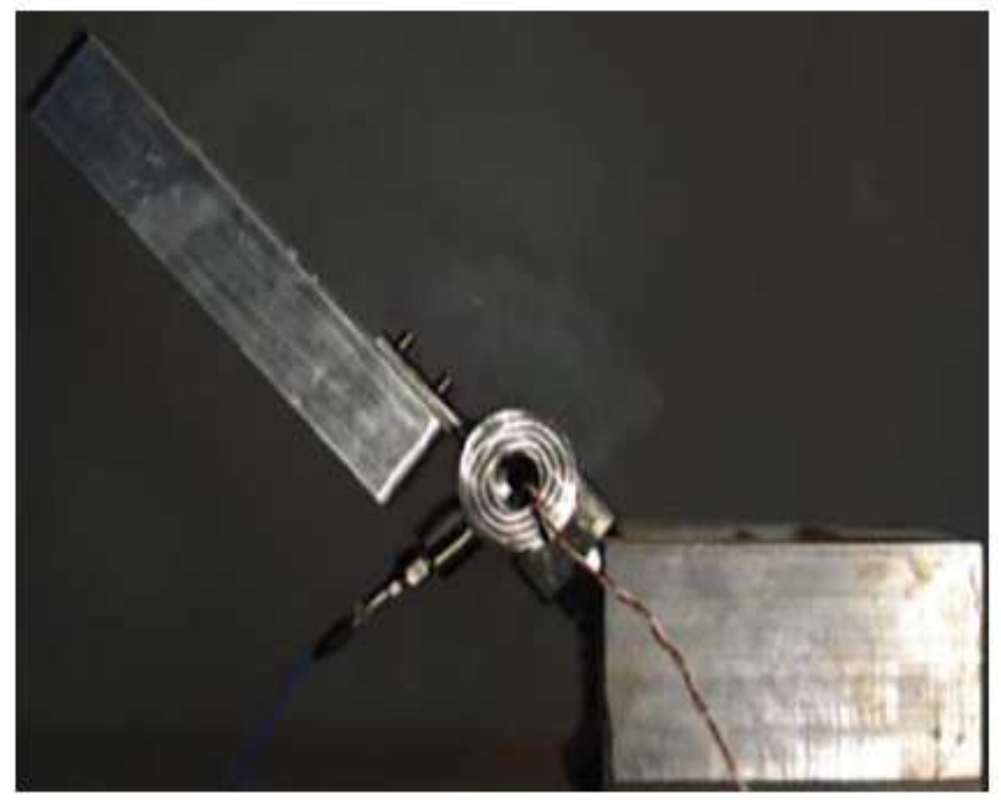

(d) Final Position of System - Test

Figure 10

Deployment images of Test-C and Adams Analysis 


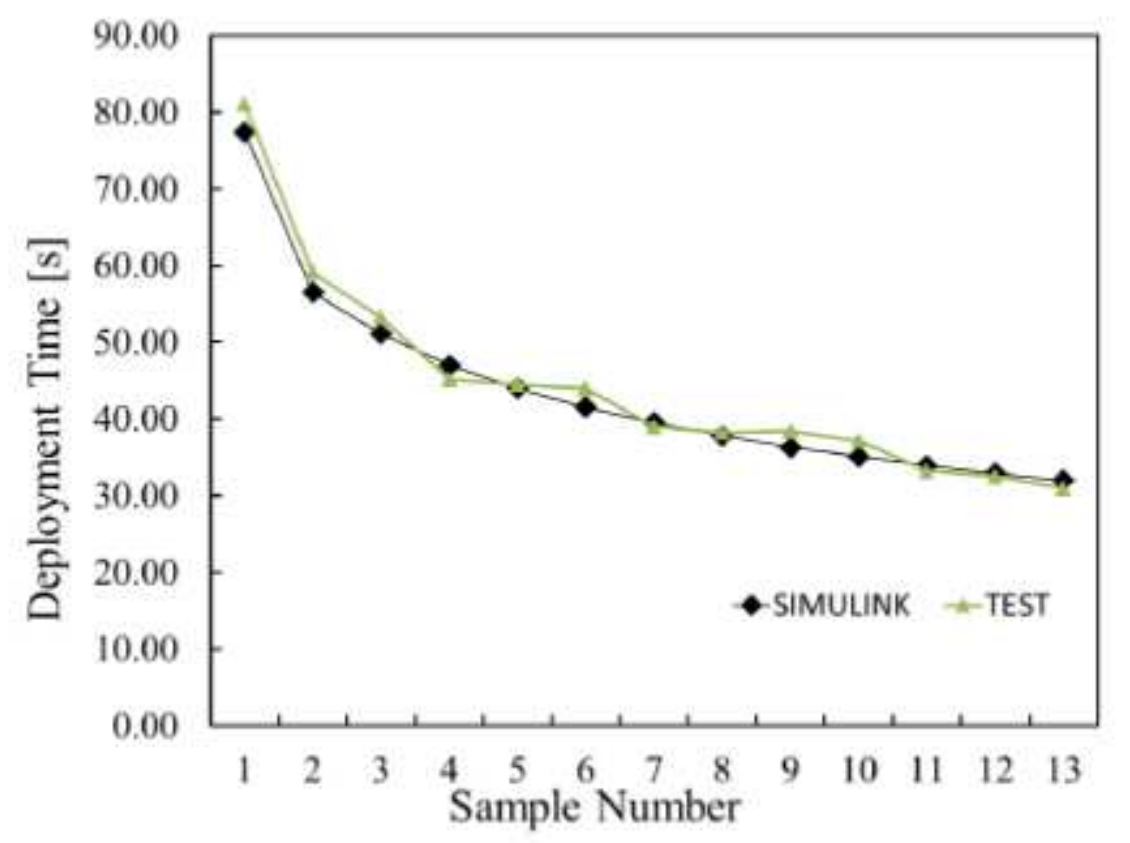

(a)

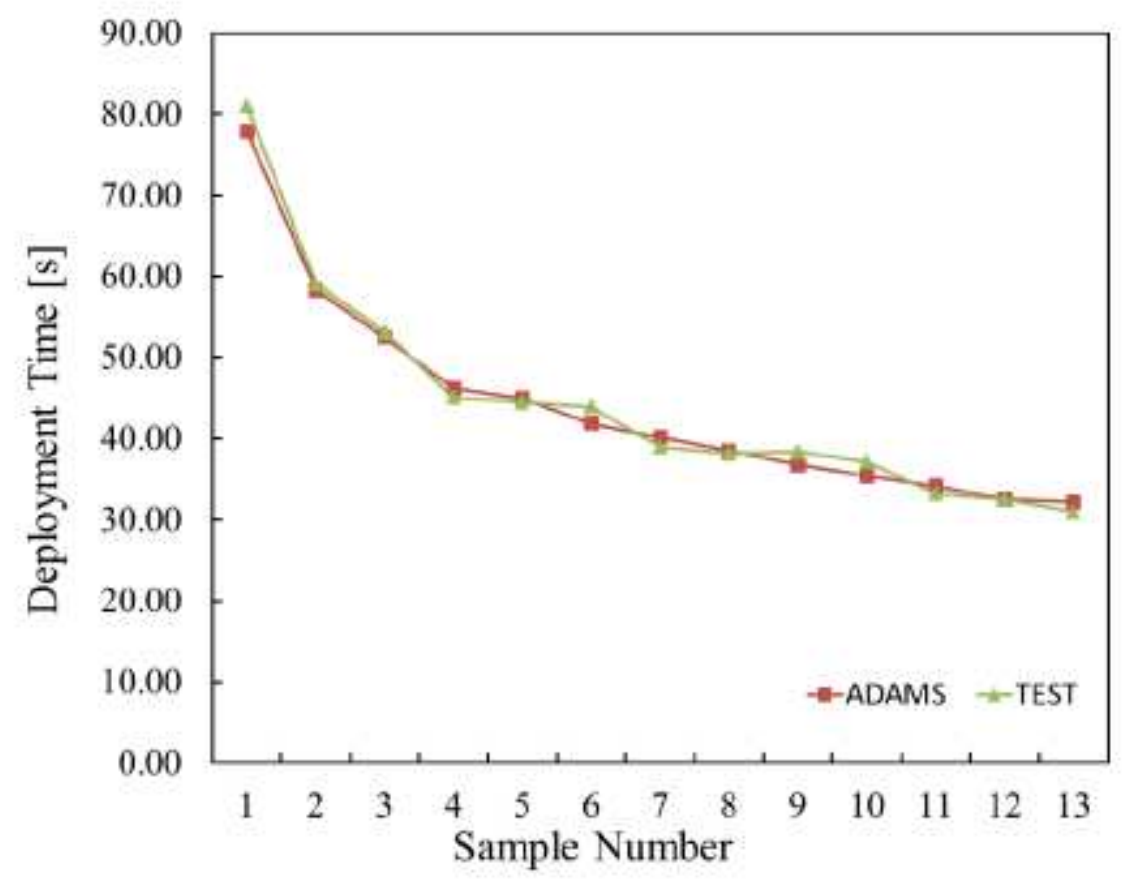

(b)

\section{Figure 11}

Comparison of deployment times of (a) Simulink Model and Test Results (b) Adams Analysis and Test Results 